\title{
Use of various obesity measurement and classification methods in occupational safety and health research: a systematic review of the literature
}

\author{
Mahboobeh Ghesmaty Sangachin ${ }^{1}$, Lora A. Cavuoto ${ }^{1 *}$ (D) and Youfa Wang ${ }^{2}$
}

\begin{abstract}
Background: This study systematically examined obesity research in occupational safety and health regarding the use of various obesity measurement and classification methods.

Methods: A systematic search of the PubMed database on English language publications from 2000 to 2015 using related keywords and search of citations resulted in selection of 126 studies. They were categorized into two groups based on their main research question: 1) general physical or mental work-related functioning; and 2) task or body part specific functioning.

Results: Regardless of the study group, body mass index (BMI) was the most frequently used measure. Over 63\% of the studies relied solely on BMI to define obesity. In only $22 \%$ of the studies, body fat was directly measured by methods such as dual energy $x$-ray absorptiometry. Abdominal obesity was defined using waist circumference in recent years, and waist-hip ratio in earlier years. Inconsistent cut-offs have also been used across studies investigating similar topics.

Conclusions: Few authors acknowledged the limitations of using indirect obesity measures. This is in part due to the limited understanding of some occupational safety and health researchers regarding the complex issues surrounding obesity classification and also the mixed recommendations over the past 2-3 decades and across populations. Efforts need to be made to promote appropriate obesity measurement and reporting in this field.
\end{abstract}

Keywords: Obesity, Overweight, Body mass index, Occupational safety and health, Ergonomics

\section{Background}

Obesity affects over 600 million adults worldwide and the number continues to grow [1]. Along with the rise in its worldwide prevalence [2,3], the evidence for its adverse effects on individuals' health has been accumulating. Obesity has been identified as a risk factor for cardiovascular disease [4], pulmonary embolism [5], large joint osteoarthritis (OA) [6], and certain types of cancer [7]. It has also been associated with a decrease in general physical function [8], as well as cognitive abilities [9]. The diversity in the adverse outcomes attributed to

\footnotetext{
* Correspondence: loracavu@buffalo.edu

${ }^{1}$ Department of Industrial and Systems Engineering, University at Buffalo, 324 Bell Hall, Buffalo, NY 14260, USA

Full list of author information is available at the end of the article
}

obesity, the complexity in the mechanisms leading to them, and the multi-factorial nature of this disease require the joint effort of different scientific disciplines to better understand the scope of the problem and to limit its detrimental effects.

With the prevalence of obesity among the workforce being equal to that of the general population [10], the occupational safety and health discipline has shown interest and effectively contributed to obesity research. The effects of obesity on work performance, physical capacity, and physical and cognitive function have been the research focus of many ergonomists, work analysts, and occupational health experts. As such, employees who are obese have been found to have higher rates of sick leave [11] and workplace injuries [12], along with 
increased employer-paid healthcare costs [13]. As these efforts expand to evaluate the relation between obesity and work [14], it is essential to explore how obesity status is measured in this field (e.g., body mass index (BMI) and body fat percentage (\%BF)) as well as the basis for classifying individuals into distinct risk groups (e.g., types I and II obesity). In general, the issue of obesity measurement is two-fold: 1) selection of the appropriate measurement and 2) properly carrying out the measurement process to minimize measurement error.

\section{Measurement selection}

The World Health Organization (WHO) defines obesity as abnormal or excessive fat accumulation that may impair health [15], and this definition should serve as the basis for measurement selection. While underwater weighing and dual energy $x$-ray absorptiometry (DEXA) directly measure body fat, many indirect measures of adiposity have been used to measure obesity status. Anthropometric measures such as the weight-for-height index, BMI, waist circumference (WC), waist-hip ratio (WHR), and body fat percentage estimated by skinfold thickness (ST) are widely accepted indirect measures. Since the 1990s, BMI has been widely used to classify overweight and obesity, both in adults and children [16]. BMI has been suggested as an ideal measure of adiposity since it is easy to measure and is closely associated with obesity related health risks [17].

However, indirect measures such as BMI, fail to distinguish between fat, muscle or bone mass and are prone to misclassification, particularly among muscular subjects [18]. Mullie et al. [19] compared \%BF, measured by bipolar bioelectrical impedance analysis (BIA), and BMI, for a cohort of 448 male military candidates and found a statistically significant difference between classifications of normal weight versus overweight. Almost $40 \%$ of the subjects classified as overweight with BMI $>25 \mathrm{~kg} / \mathrm{m}^{2}$ had a \%BF corresponding to normal weight. Similarly, Deurenberg et al. [20] observed a higher rate of misclassification with BMI compared to DEXA in 416 European individuals. This study showcased how individual results based on a single classification method should be interpreted with caution.

Reliance only on BMI can also lead to misclassification of those with excess body fat, but BMIs corresponding to normal weight. These "metabolically obese but normal weight" [21] individuals share many health risks with those categorized as obese both based on BMI and $\% \mathrm{BF}[22]$. The elevated visceral fat observed in this category is accompanied by increased levels of both liver and muscle fat [23]. In a workplace study, comparing new industry hires from 1990 to 1992 and from 2000 to 2002, there was no significant difference in BMI but a significant difference in \%BF, measured by ST [24].
There were also significant differences in physical fitness as measured by timed sit-ups and squats, suggesting that employers would miss information regarding their employees' fitness with reliance on BMI only. BMI is also not independently representative of body fatness. Significant dependencies on age and sex were observed in the relation between \%BF and BMI in a study of 706 adult men and women [25]. BMI also overlooks the distribution of fat, which is an important factor in disease risk. For instance, android fat distribution (also referred to as abdominal, central, visceral, or upper body fat distribution) causes increased risk of diseases such as cardiovascular disease and type 2 diabetes [26], while gynoid fat distribution (i.e. larger hip and thigh circumferences) does not seem to have similar effects [27]. Indices such as WC and WHR are useful in characterizing the obesity morphology, particularly for studies where a difference in anthropometry among subjects is relevant to consider.

Misclassification and measurement error may be exacerbated in small sample sizes, which are common in exploratory laboratory-based occupational safety and health studies. Piers et al. [28] showed that despite the significant correlation between $\mathrm{BMI}$ and \%BF (measured by underwater weighing method) of the 117 healthy samples, BMI only explained, on average, $50 \%$ of the variance in $\% \mathrm{BF}$. The reported poor sensitivity $(47.7 \%)$ and positive predictive value (67.7\%) of BMI makes it an unreliable measure of obesity in individuals. These findings not only suggest the inadequacy of BMI in classification of obesity status, particularly for individuals near the cutoff values, but also point out the importance of a rigorous obesity classification in studies with small sample sizes.

\section{Measurement process and method}

After selection of the suitable and hypothesis-relevant obesity measure, it is the researchers' responsibility to ensure that the measurement guidelines are thoroughly followed to reduce measurement error. For instance, WC is widely accepted as a simple and reliable measure of obesity in general, and abdominal obesity, in particular. There exist guidelines to ensure WC is appropriately measured [29, 30]. However, Agarwal et al. [31] found significant differences in the measured WC across varying anatomical sites, phases of respiration, and time since last meal, when following either the WHO or the National Institute of Health (NIH) guidelines. Overlooking these details can lead to an increase in the measurement error and the steps taken to control them should be acknowledged in publications.

Similarly, the cut-off values used to classify subjects into distinct risk groups are also worth scrutiny. For instance, WHO identifies 25 and $30 \mathrm{~kg} / \mathrm{m}^{2}$ as BMI cut points for overweight and obesity respectively. However, it has been shown that among certain populations (e.g., individuals of 
Asian descent) cardio-metabolic risk is increased at lower body mass indexes [32]. While some researchers advocate using international cut-offs [33], some find nationally and ethnically selected cut points, when available, more advantageous [34]. Overall, inconsistency in the cut-offs used across studies with similar topics is detrimental to the strength of the body of evidence.

This study aims to examine the obesity-related research in occupational health and safety regarding obesity measurement methods. The findings will show how researchers in the aforementioned fields are conducting obesity research and will inform future obesity research in the occupational safety and health domain.

\section{Methods}

\section{Research strategy and study inclusion criteria}

A systematic review of the PubMed database was undertaken with the following MeSH terms: ('Work 'or 'Ergonomics' or 'Biomechanics $\backslash$ Biomechanical' or 'Occupational' or 'Motion' or 'Movement') and ('Obesity' or 'Skinfold Thickness'). In addition, a keyword search using Google Scholar and manual search of citations from relevant papers and literature reviews was done. The search was limited to journal articles dated between January 1, 2000 and December 31, 2014, published in English and studied human adults. An initial search was performed on 3 March 2015, and repeated on 24 September 2015 to update the search and results.
The study inclusion criteria were: (a) publication contributed to occupational health and safety rather than health promotion and (b) weight status was the independent variable or the major covariate included in the analysis and not the dependent variable. Review papers, simulation-based studies [35], and studies including normal weight subjects loaded with excess weight [36] were also excluded.

The initial search resulted in 3283 studies. The first author assessed all search outcomes by title and/or abstract, out of which 950 were selected based on relevance of the topic. A review of the abstracts reduced the number of studies to 111. Manual searches of the references from these studies and Google Scholar added 15 studies that were not initially captured. Overall, 126 studies were selected (see Fig. 1).

\section{Selected studies review process and data extraction}

Selected articles were reviewed and the following information was extracted: publication year, country of origin (based on the first author), main research question, design, outcomes measures, subject population, primary method of obesity measurement and the corresponding cut-offs used, whether or not subjects' weight status was self-reported, additional obesity classification methods applied, the statistical method used, sample size and number of subjects in overweight/obese $(\mathrm{OW} / \mathrm{OB})$ subgroup, whether or not the study included women in the

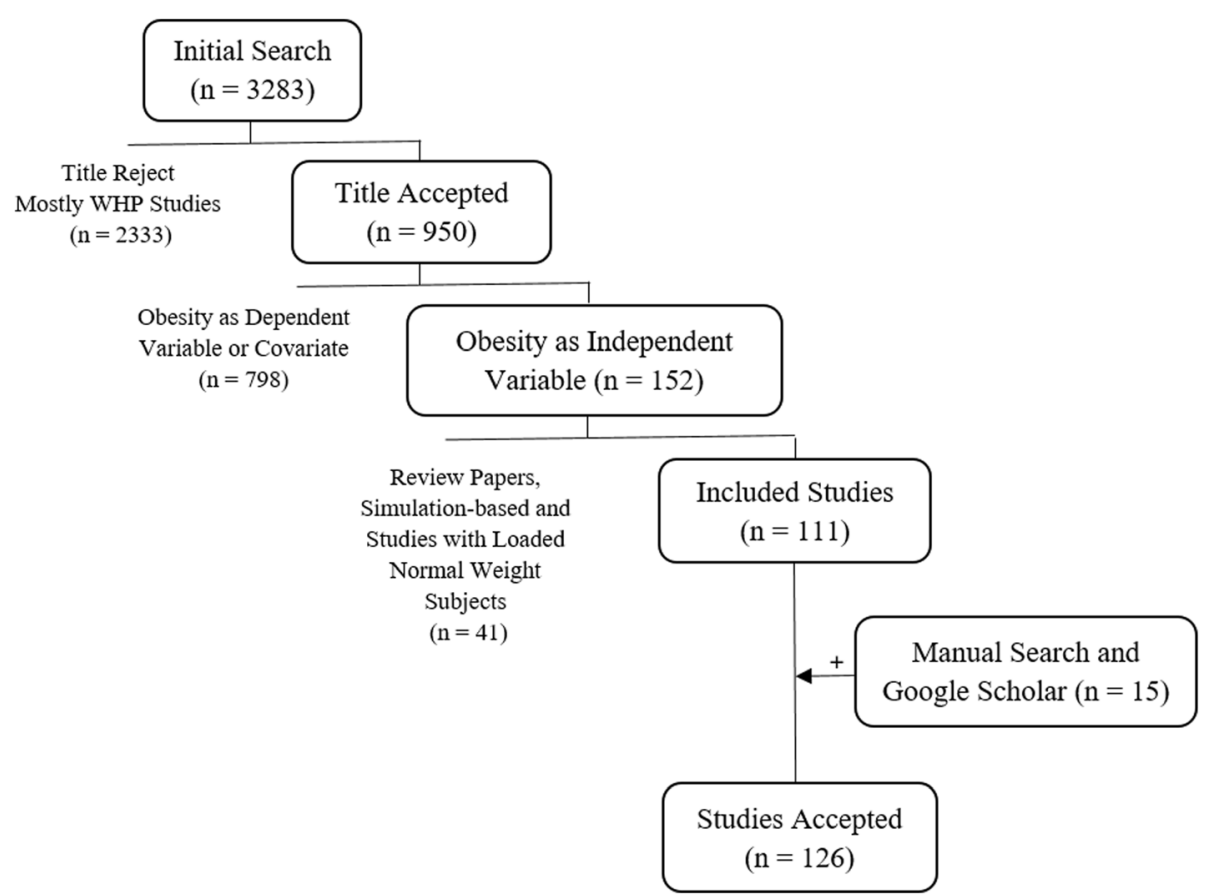

Fig. 1 Flow Diagram of Study Selection. WHP indicates studies of Worksite Health Promotion that have addressed obesity. Search was also limited to studies that aimed to assess the effect of obesity on occupational or general physical functioning, rather than work-related risk factors for obesity. Studies using simulation software and loaded normal weight subjects were also excluded 
sample, the main finding and if the results indicated significance of the obesity (and overweight if applicable) effect, and finally if the authors mentioned any potential limitations of the obesity measurement method they have used. For studies carried out in a controlled lab setting where normal weight and overweight/obese subjects were compared, the mean BMI (or any other primary obesity classification measurement) of the overweight/ obese group was extracted.

\section{Analysis}

The main research question was categorized into two types: 1) general physical or mental work-related functioning (GF) and 2) task or body part specific functioning (TBS). The summary of all included studies, together with details about the study relevant to obesity classification are presented in Tables 1 and 2.

\section{Results}

Within the selected time period (2000-2015), there has been an increasing trend in the number of studies published (see Fig. 2), with 2013 having the maximum number of publications $(n=23)$. This increase is mostly owed to the expanding interest in the specific effects of obesity rather than the general effects, which have been steadily studied by, on average, $n=2.4(\mathrm{SD}=1.9)$ studies per year. Overall, among all included studies, $63 \%$ relied solely on BMI to distinguish obese from non-obese and further classify them into distinct obesity status sub-groups (see Fig. 4). This is particularly concerning because some of these were lab-based studies with sample sizes as small as 12 or used young adults or older adults enrolled in aging research as subjects. In the following sections, studies focused on general vs. specific effects of obesity are discussed separately.

\section{Category 1: General physical or mental work-related functioning}

Among the 126 reviewed studies, 37 were related to the general effects of obesity as they pertain to occupationally-relevant outcomes such as performance, disability and discharge rate, healthcare cost, and overall well-being (see Table 1$)$. The majority (64\%) of the studies were from North America (see Fig. 3). Over the period of the review, the topic of general studies has gradually moved from work performance and workplace costs associated with obesity to the potential reasons behind elevated costs and poor performance, such as musculoskeletal symptoms and mental health issues. These studies applied a wide range of designs, with cross-sectional being the most frequent (15), followed by longitudinal prospective studies (13). Participants in 10 studies were army personnel, police officers, or career firefighters and the rest were either civilian labor force
(20) or their occupational status was not reported or relevant to the topic (7).

With regard to the measurement of obesity and group classification, in over $71 \%$ of these studies BMI was the only obesity measure used to distinguish obese from non-obese (see Fig. 4), with about $57 \%$ of these studies using self-reported weight and height to calculate BMI. About 13\% of general studies used additional anthropometric measures such as WC and WHR to enhance obesity measurement accuracy. Finally, of the 6 studies using a direct adiposity measure, 5 were studies of army personnel, fire fighters, or police officers. Four studies reported using cut-off values other than 25 and $30 \mathrm{~kg} / \mathrm{m}^{2}$ to categorize subjects into distinct BMI subgroups, out of which two were army studies, one included Asian participants, and one provided no justification to use $\mathrm{BMI} \leq 26 \mathrm{~kg} / \mathrm{m}^{2}$ as the cutoff for grouping. The median sample size was 1284 (14-69,515). With the exclusion of two studies that did not report the number of obese/overweight subjects included in their sample, on average $55.7(0.2) \%$ of the samples consisted of OW/OB. Only 5 studies in this category provided information regarding the mean body mass index (or any other primary obesity classification measurement) of the $\mathrm{OW} / \mathrm{OB}$ group. Overall, in 11 studies, the authors discussed the possibility of subject misclassification due to a reliance on BMI as the sole indicator of obesity status, either as a justification to use additional measures (2 studies) or as a limitation.

\section{Category 2: Task or body part specific functioning}

The majority of the reviewed studies (89) investigated a wide range of specific effects of obesity (see Table 2). North America and Europe contributed by 45 and 39\% of such studies, respectively (see Fig. 3). Authors from Italy in particular contributed $16 \%$ of the publications, ranking higher than Asia and Australia, with five and six studies respectively. It should be noted that region of origin did not systematically affect the measurement approach used. Although the majority of the studies in this category were laboratory-based observational studies, BMI was still the most frequently used measure, with $59 \%$ of the studies relying solely on it to distinguish obese from non-obese. Study topics varied broadly, however, they were categorized in seven groups based on their main hypothesis and research focus (shown in Table 2). These groups, ordered based on number of studies, are discussed in more details as follows.

Twenty-three studies $(\sim 26 \%)$ discussed how obesity alters outcomes related to gait, such as metabolic cost, preferred speed, spatio-temporal parameters, and joint moments. From 2006 to 2014, at least one study related to the effects of obesity on gait was published each year. All of the studies in the gait category were lab-based observational studies. While other studies recruited 


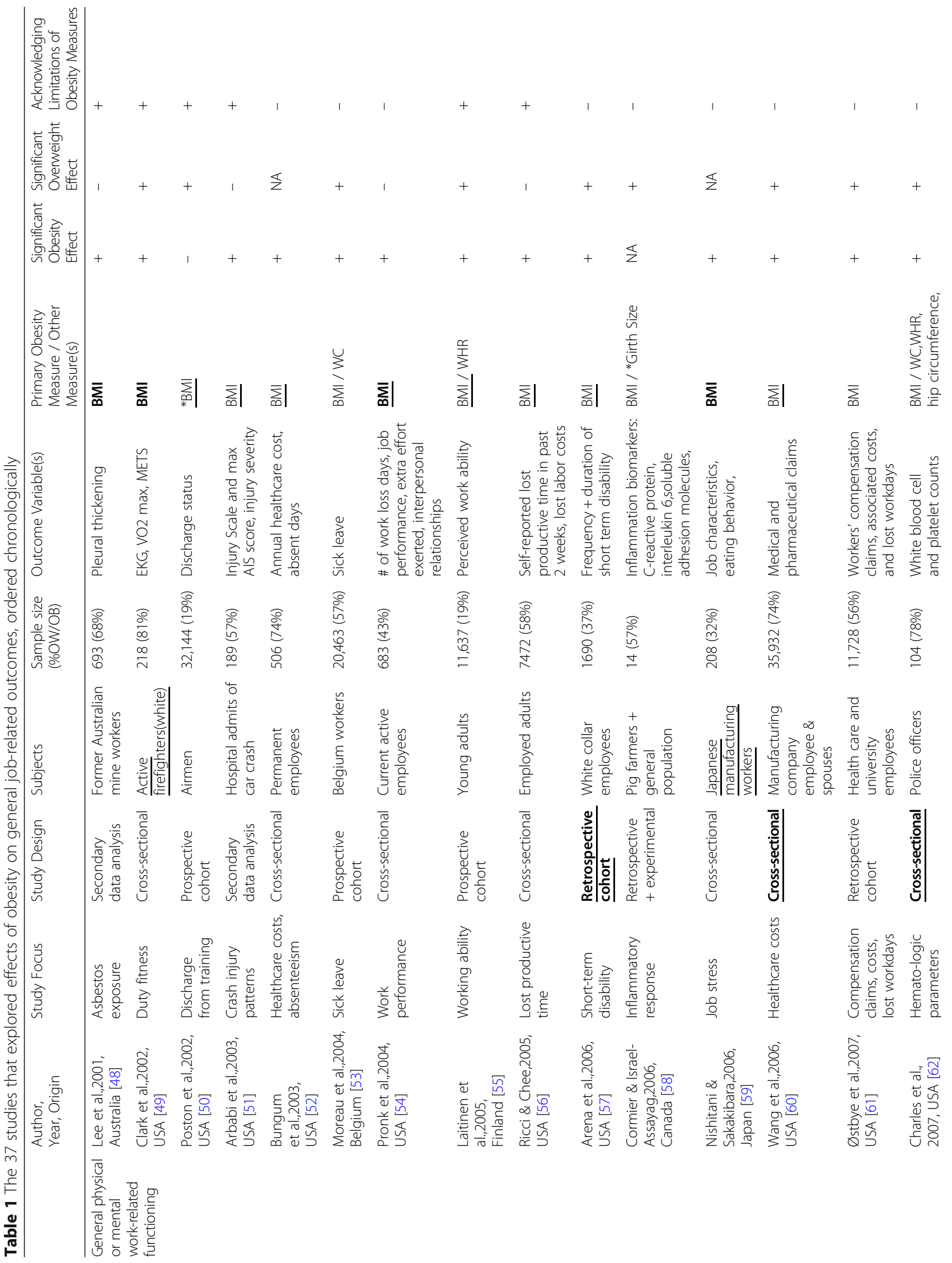




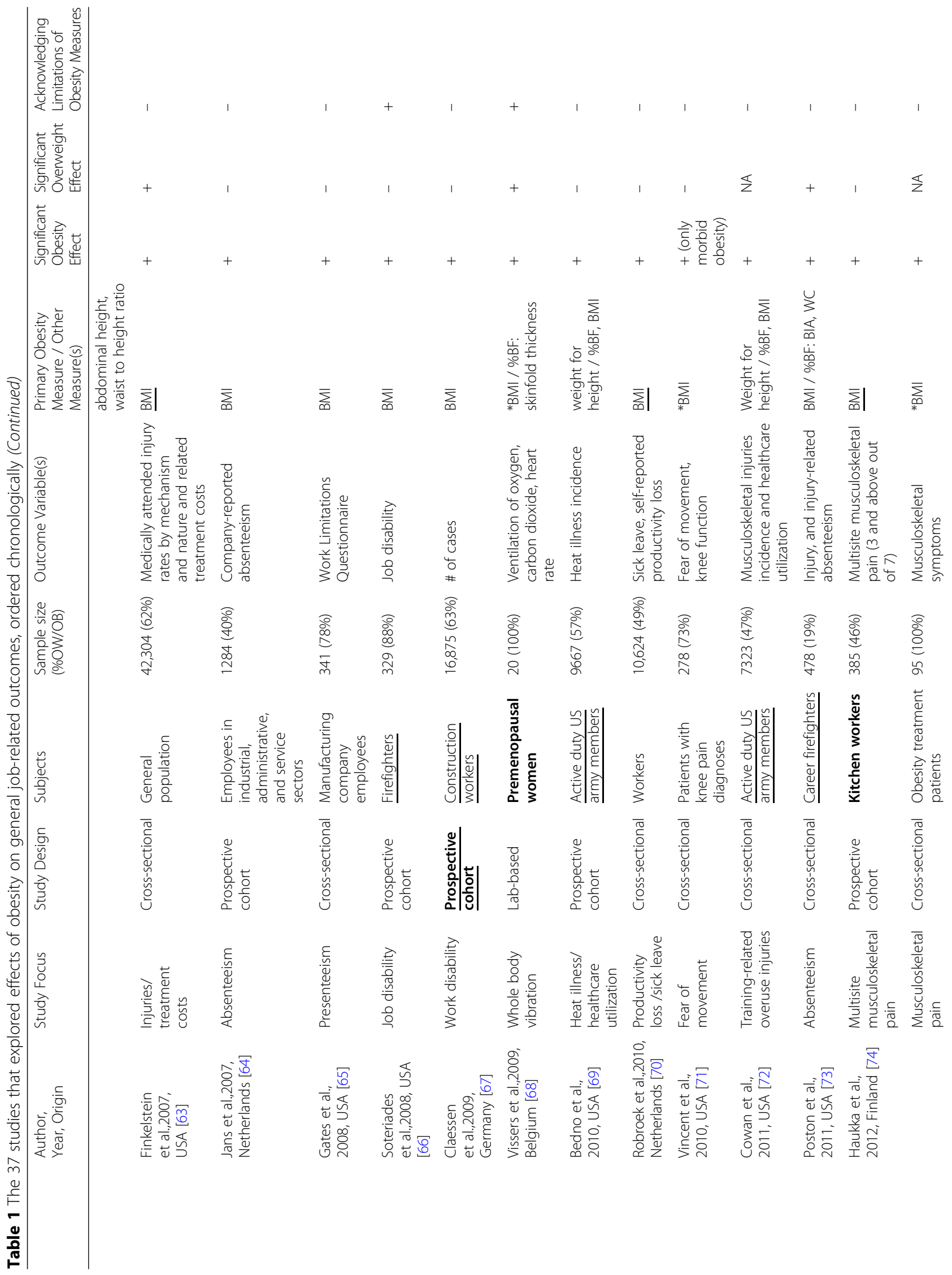




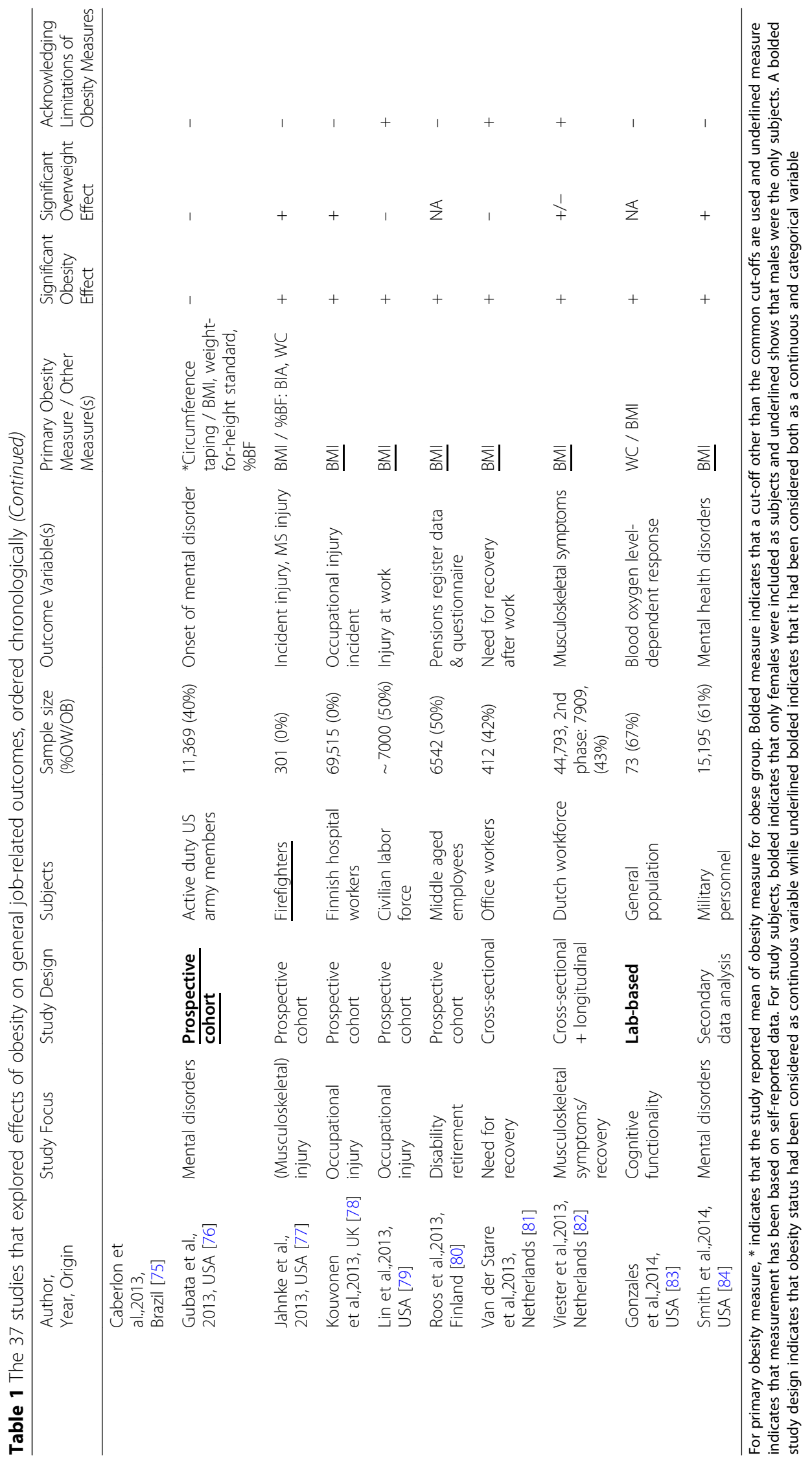




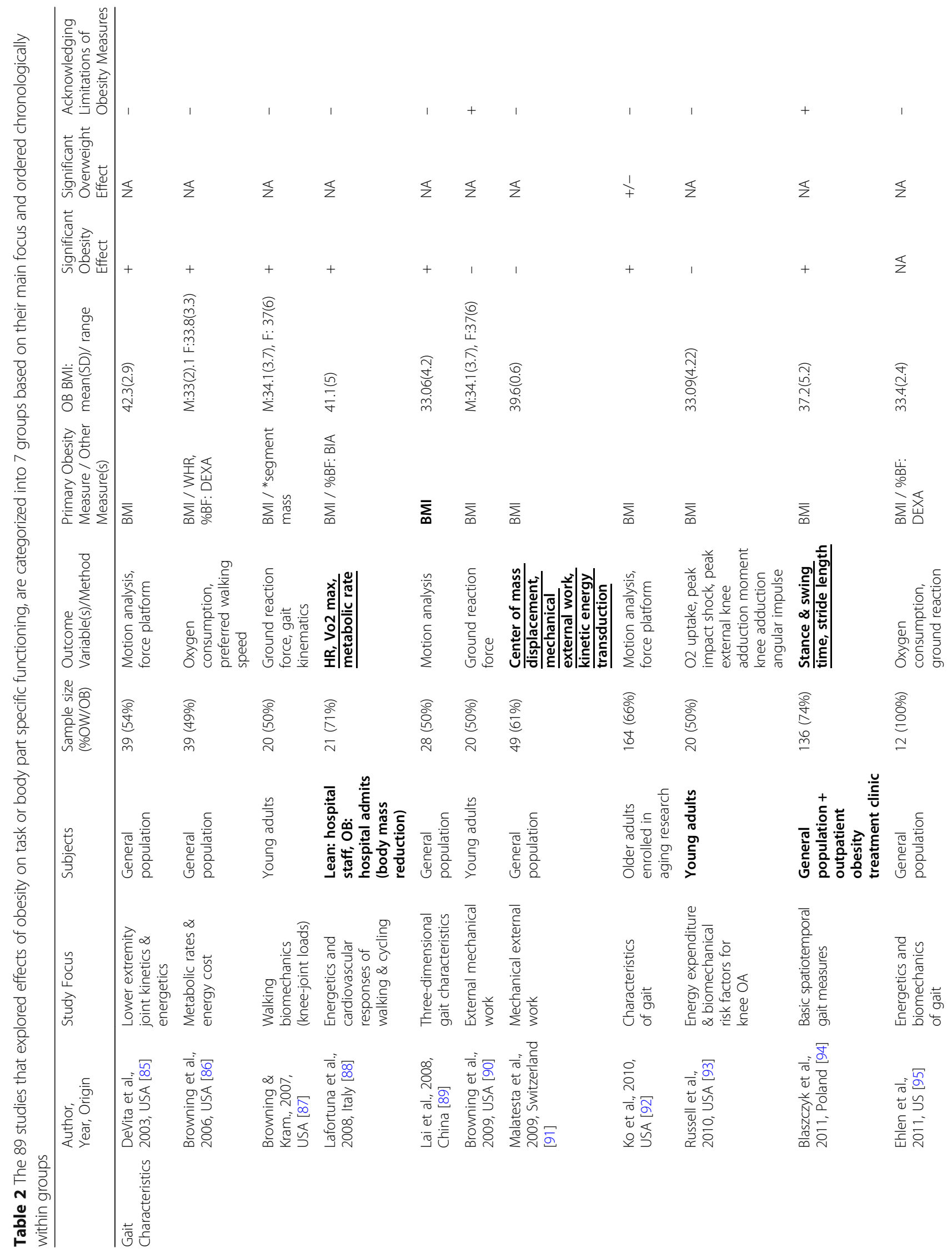




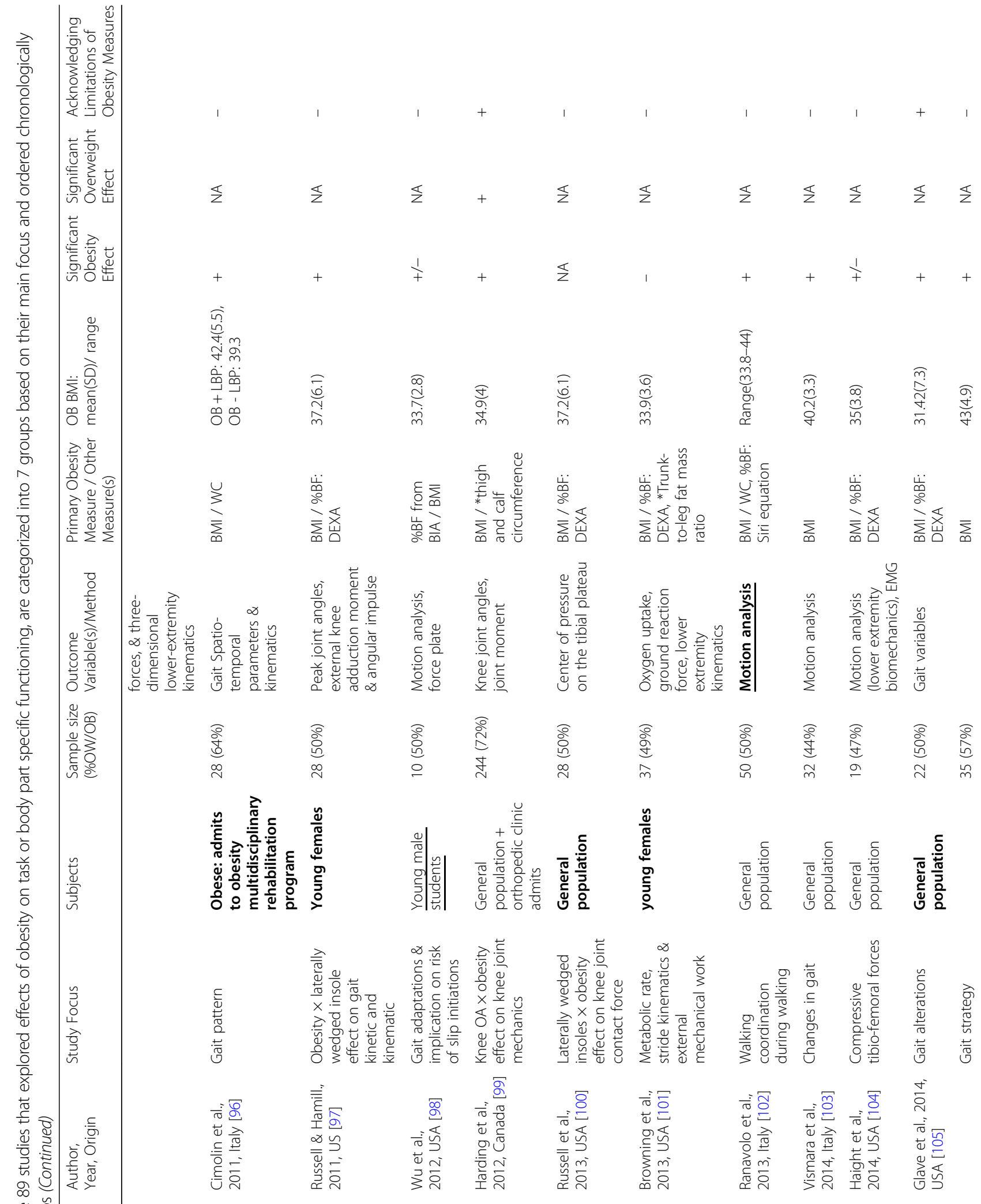




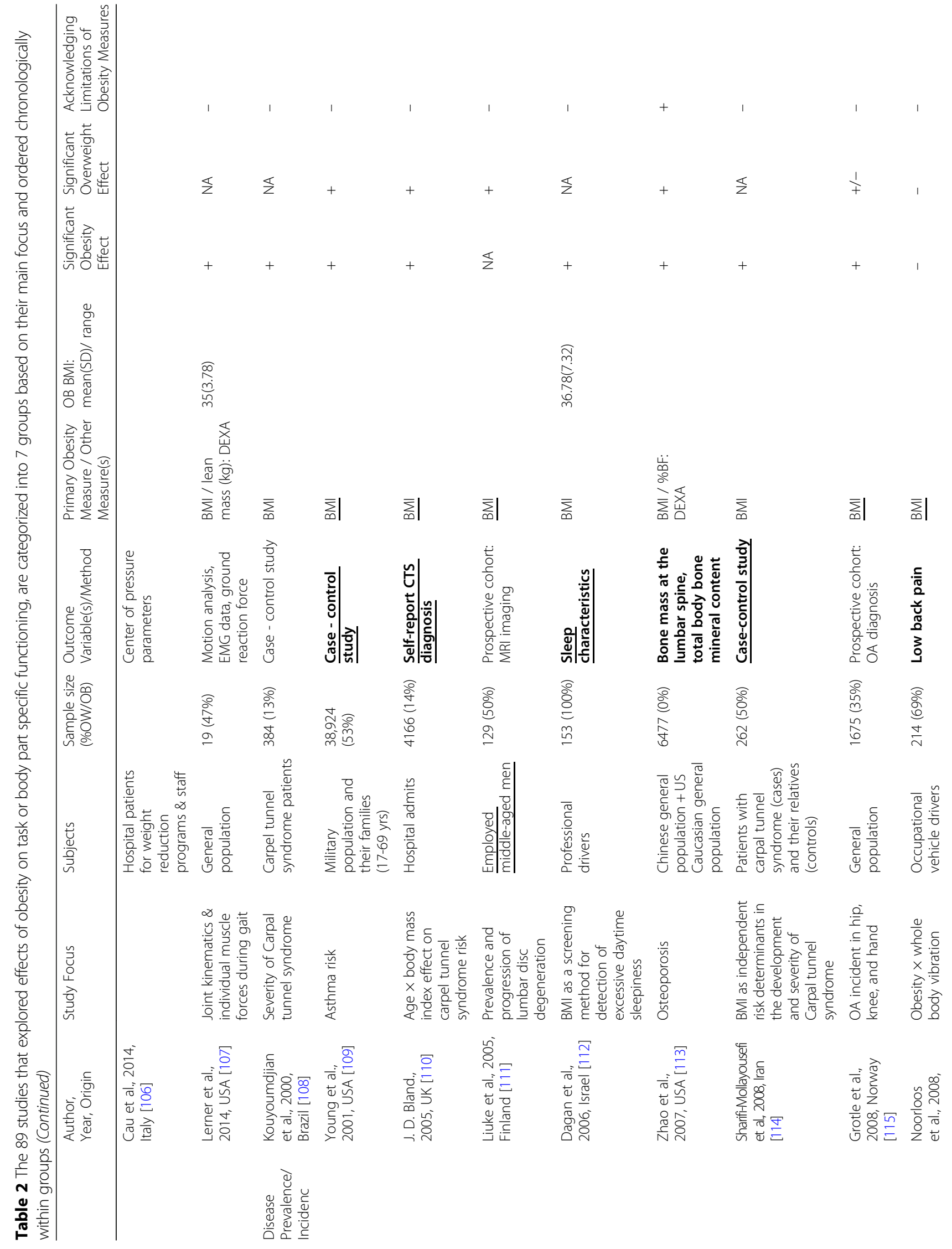




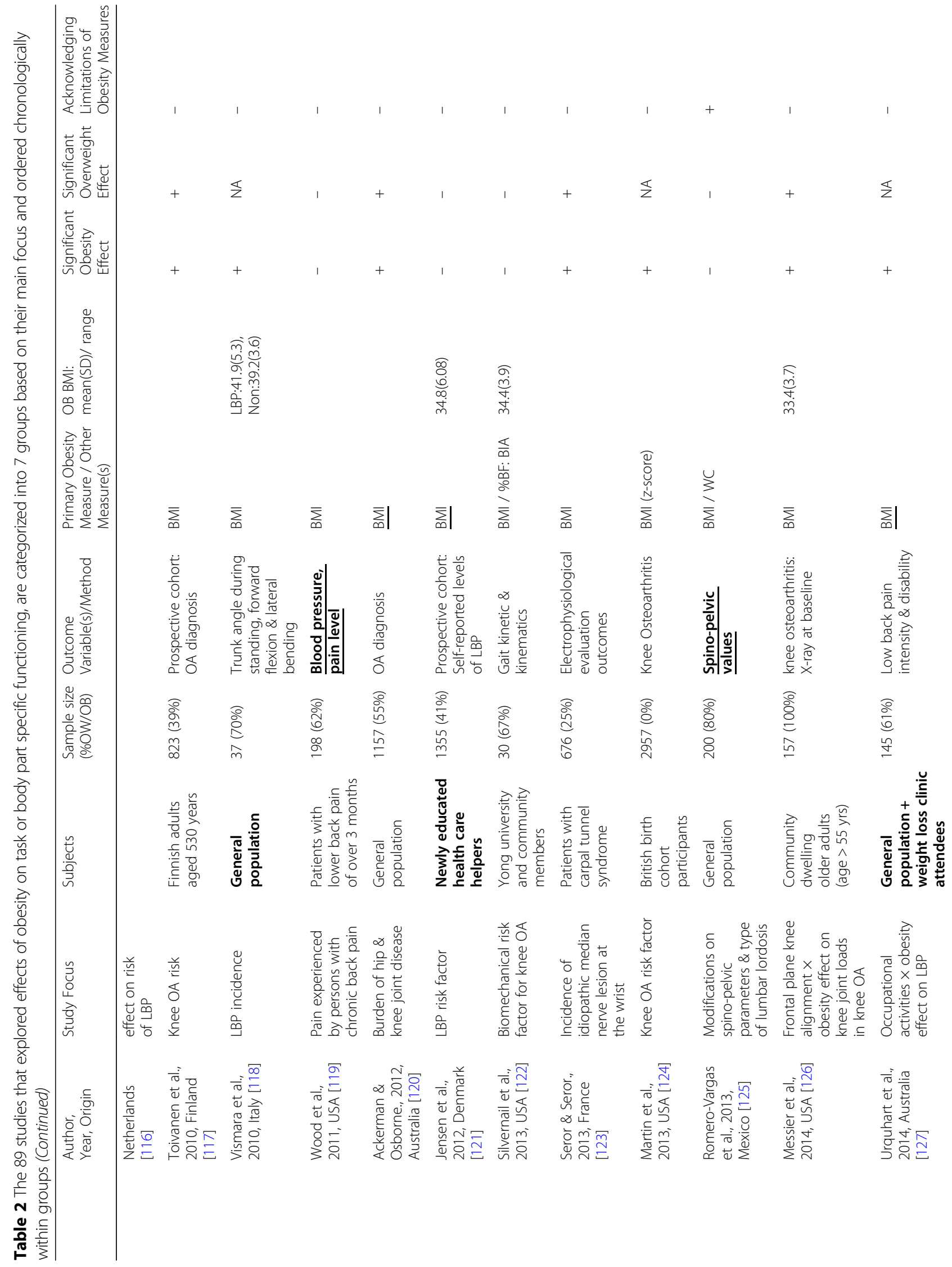




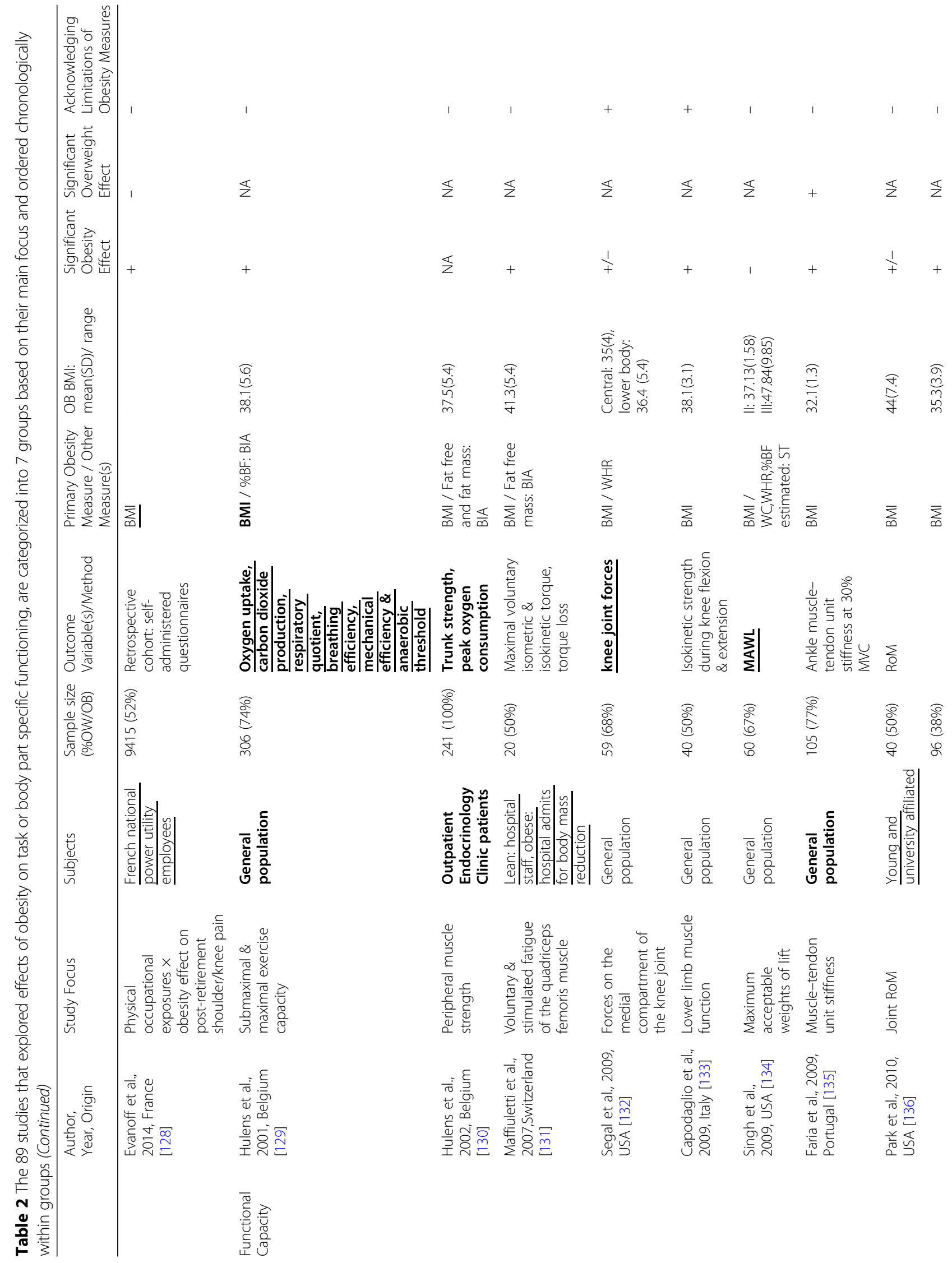




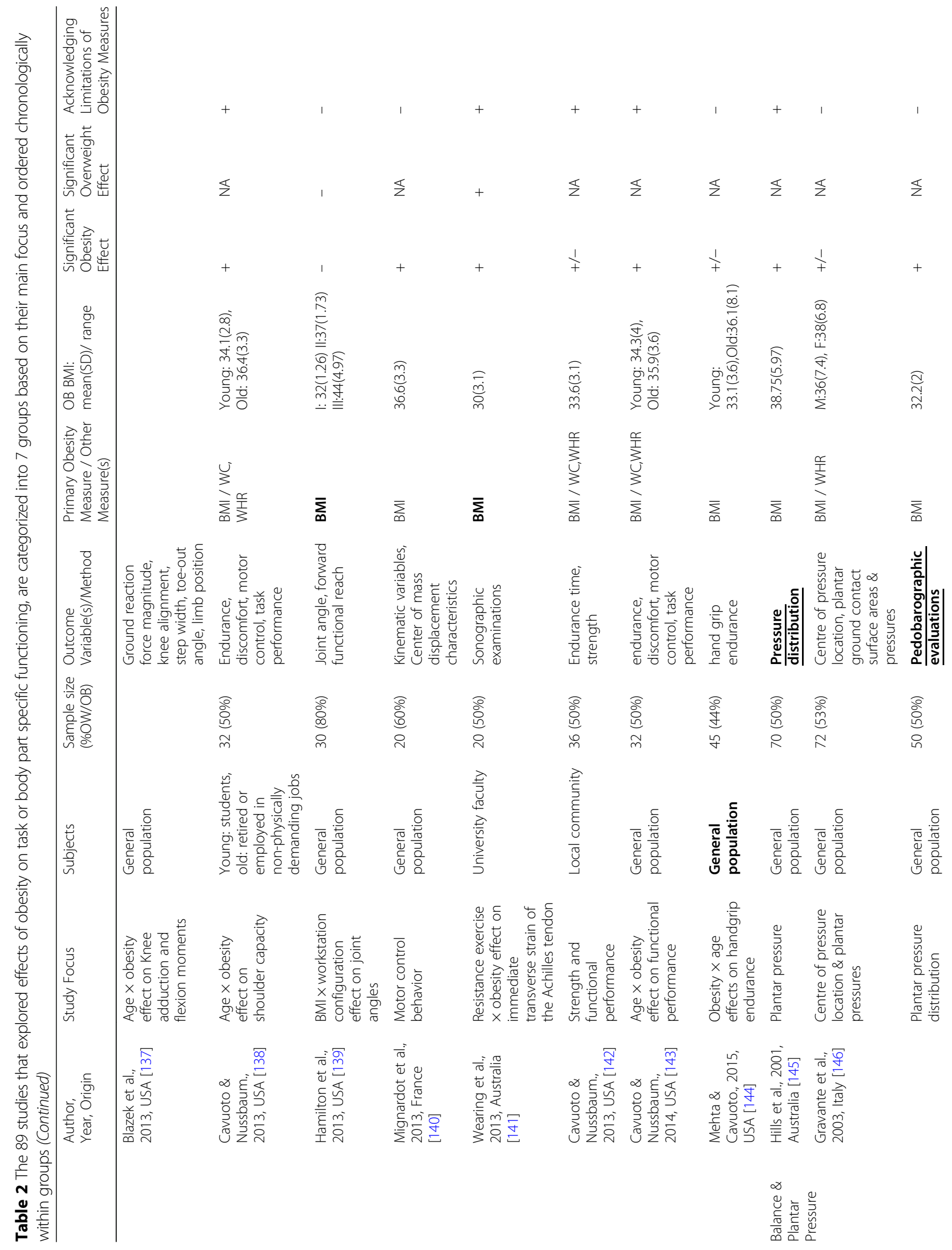




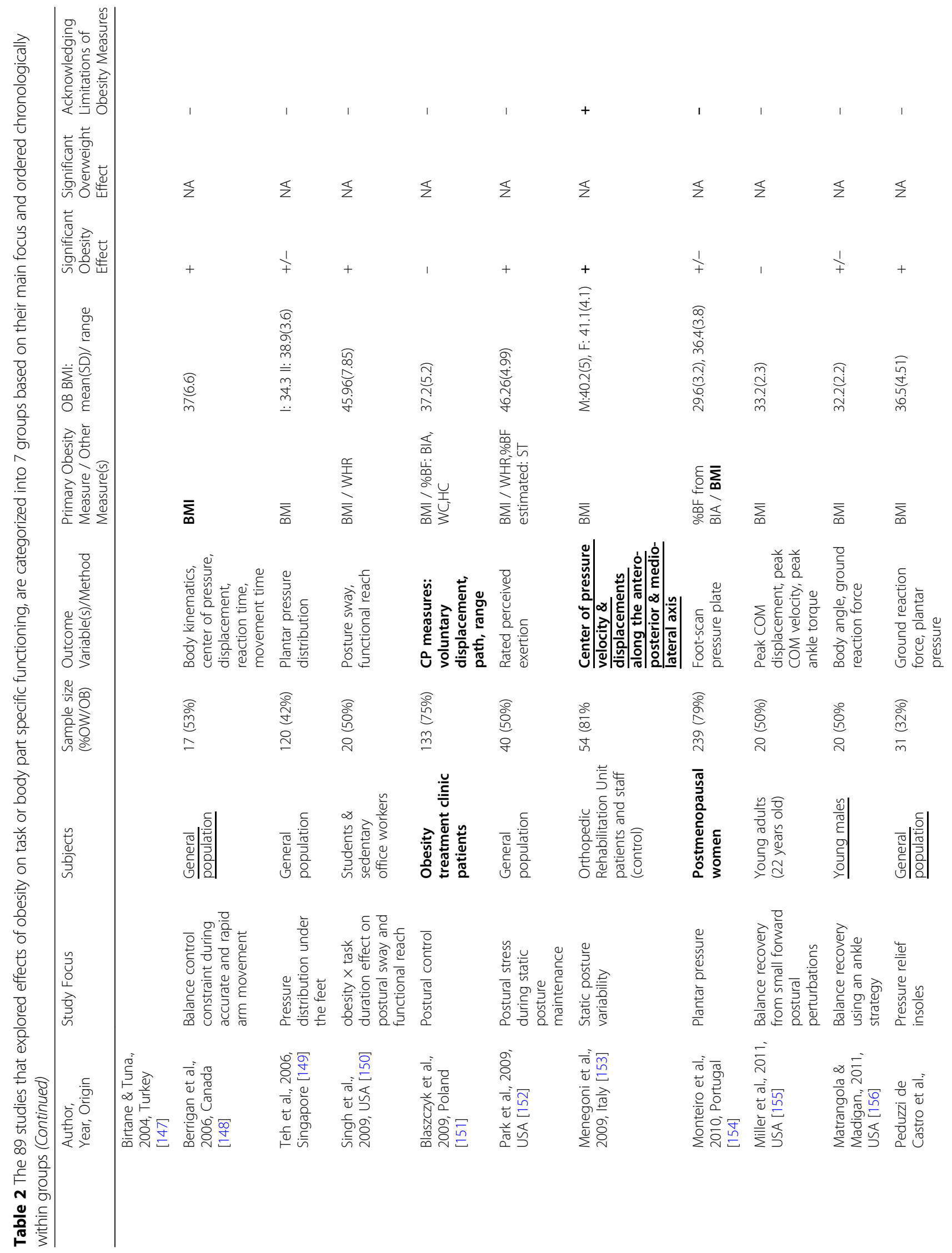




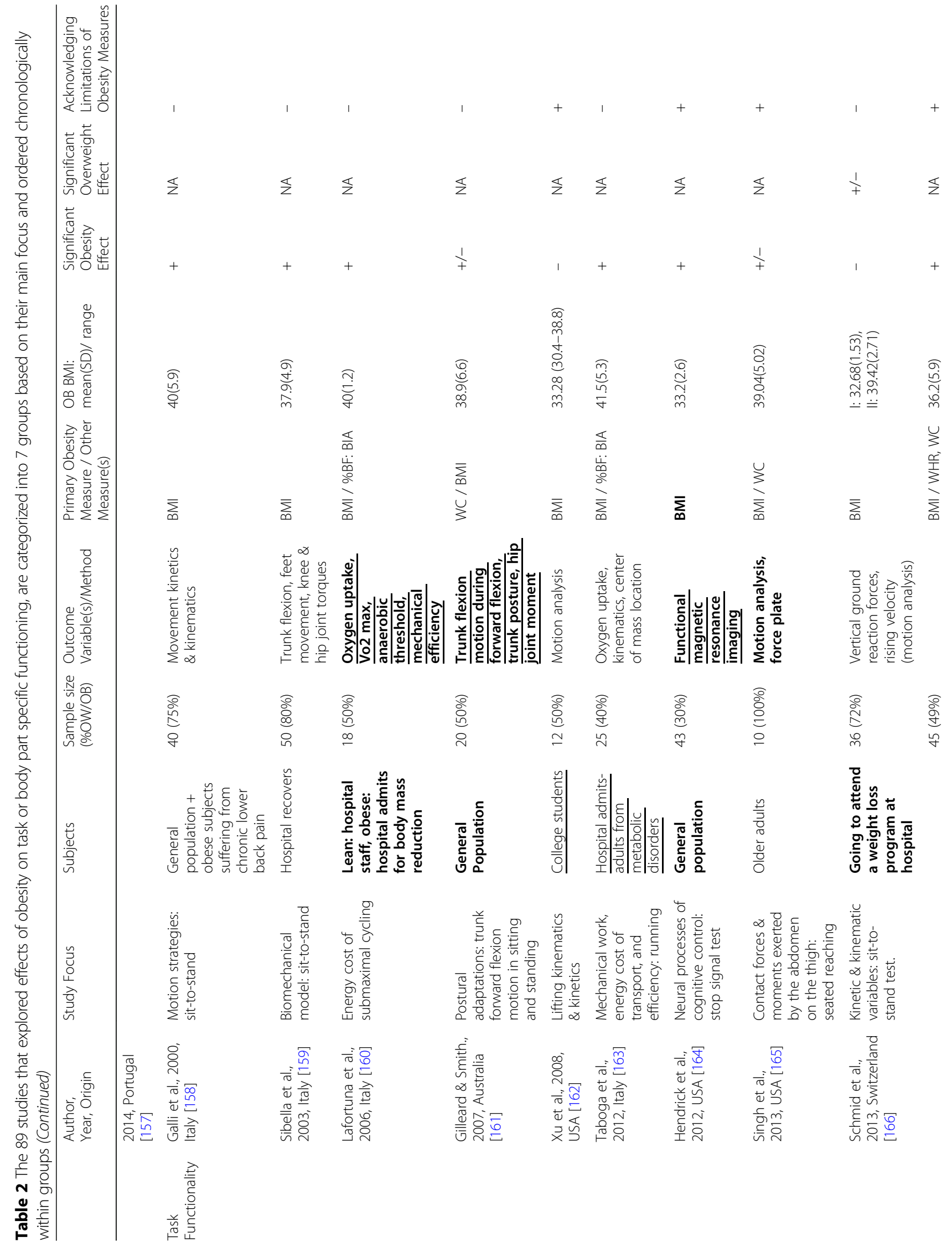




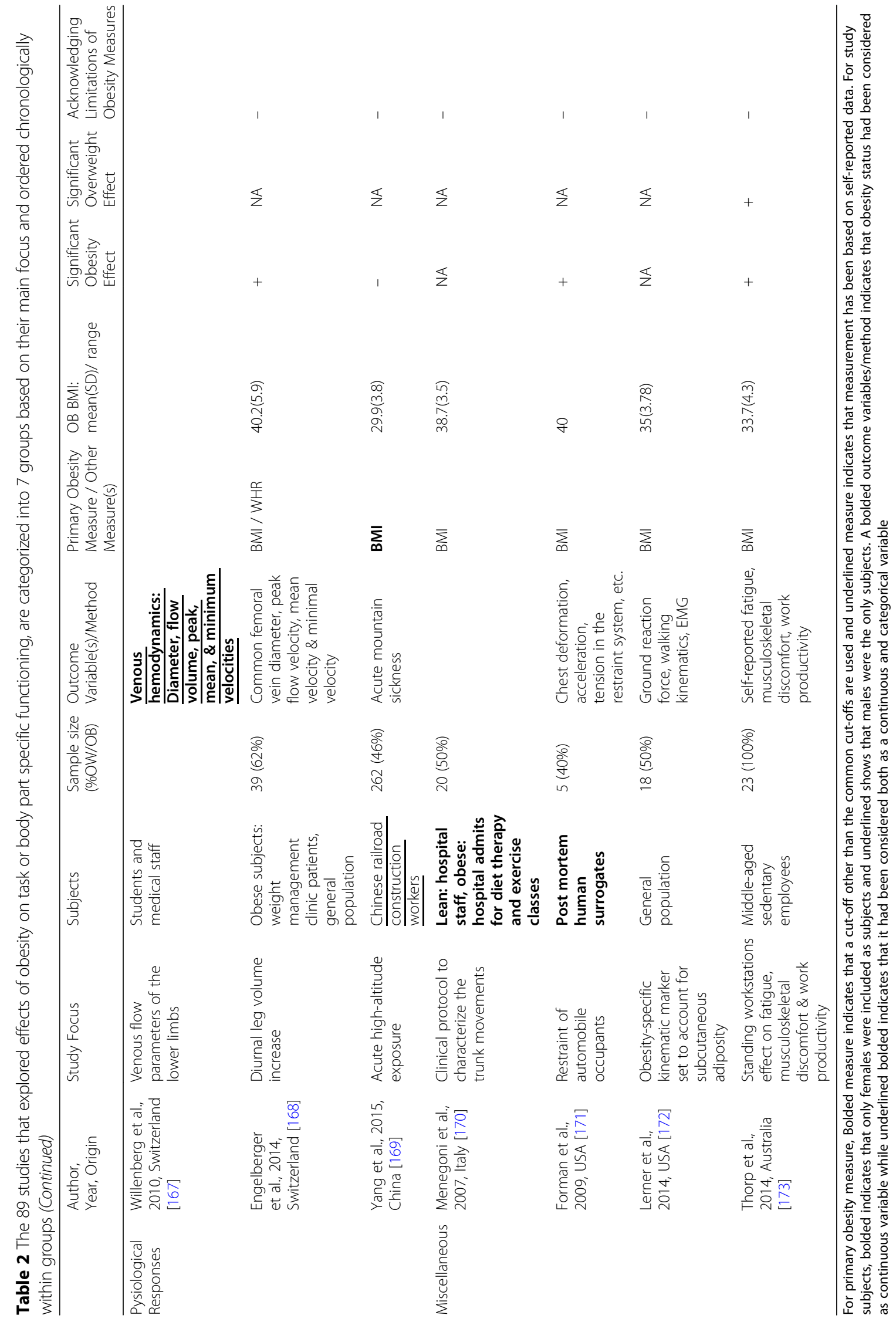




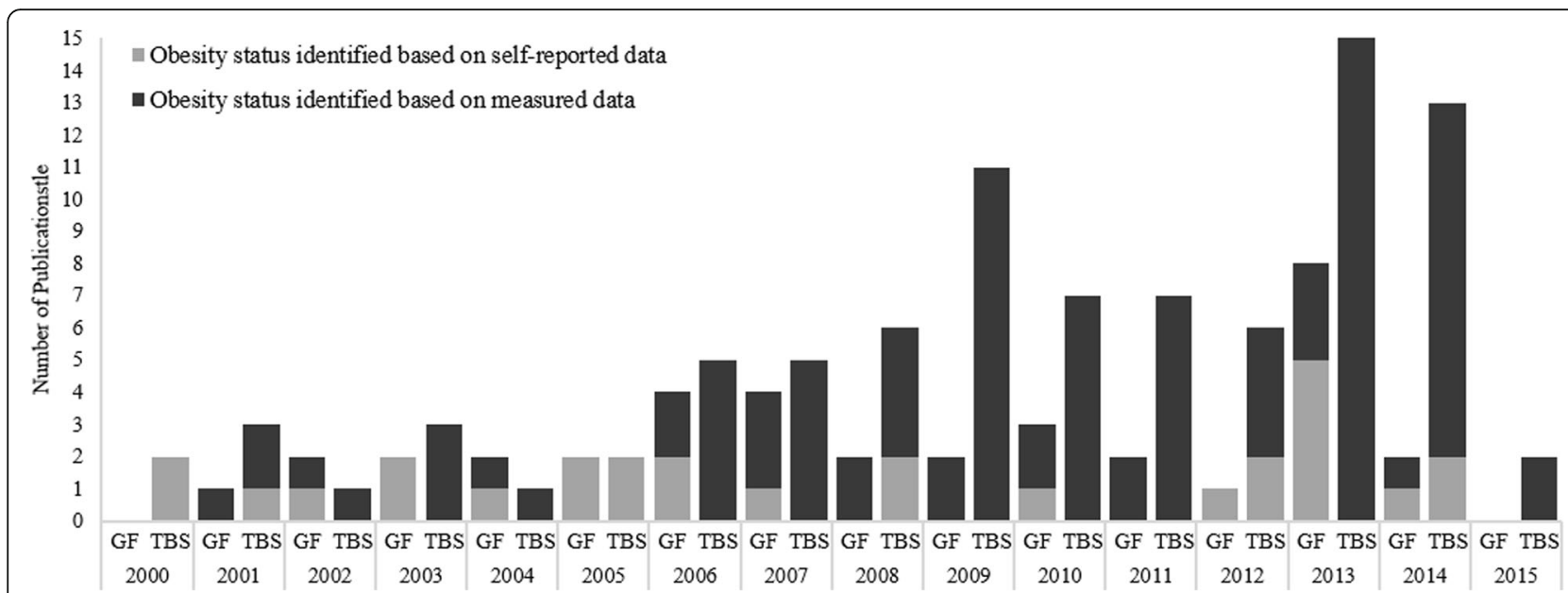

Fig. 2 Over the period of the review, there was an increasing interest in obesity research

subjects from a general population, obese subjects in three European studies were females, sampled from obesity clinics. The median sample size was $28(10-244)$. More than half of the included subjects (56.7\%) were categorized as OW/OB (only two had an overweight group). There were 11 studies which used BMI only (see Fig. 5). With the exclusion of the studies which reported sex or condition-stratified averages (4), the average BMI for nine studies were $\leq 35 \mathrm{~kg} / \mathrm{m}^{2}$, four were $\leq 40 \mathrm{~kg} / \mathrm{m}^{2}$ and four were $>40 \mathrm{~kg} / \mathrm{m}^{2}$. All but four studies reported a significant main effect for obesity or overweight on their outcomes of interest. It is noted that three of the

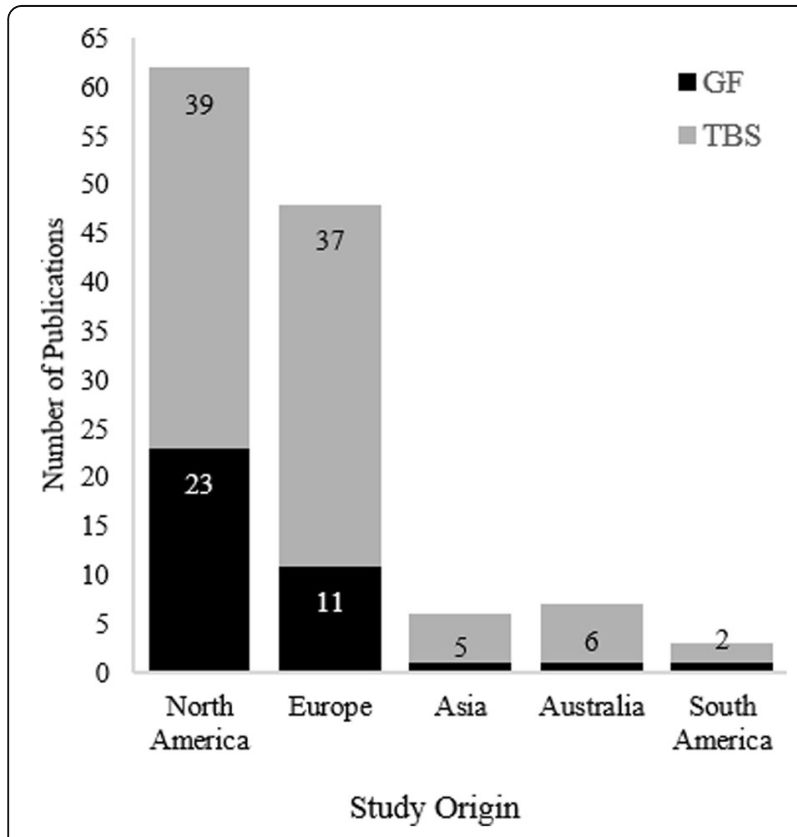

Fig. 3 The origin of the studies. As expected, North America had the highest number of publications in both GF and TBS categories studies reporting non-significant results used BMI as the sole obesity measure.

The next largest group focused on the prevalence, incidence, burden, and changes in symptoms of diseases such as carpel tunnel syndrome, osteoarthritis, low back pain (LBP), asthma, and sleep disorders in association with obesity. This category included some large scale public health studies, hence there was more diversity in terms of study design. The median sample size was 384 $(30-38,924)$. With the exclusion of two studies that did not report the proportion of $\mathrm{OW} / \mathrm{OB}$, on average 54 (24) \% of the samples were obese or overweight. Six studies used patients and hospital admits as participants and six studies reported subjects belonging to a certain occupation. Eighteen studies relied solely on BMI, two added \%BF and one added WC. Sixteen studies failed to report the obesity class of the obese group. In the four that did, all but one had mean $\mathrm{BMI} \leq 35 \mathrm{~kg} / \mathrm{m}^{2}$. Only two studies, which both had one additional obesity measure, mentioned the inadequacy of BMI.

Changes in functional capacity were the topic of 16 studies. Functional capacity encompasses all topics related to muscle strength, endurance, functional reach, range of motion (RoM), and motor control behavior. Participants in two studies were outpatient clinic or hospital patients (endocrinology and body mass reduction admits) and the rest were recruited from the general population. Eight studies used BMI as the primary and only obesity measure, while three studies also measured body fat. Four studies augmented BMI with other anthropometric measures and one study reported using four obesity measures including both direct and indirect. While no studies relied on self-reported height and weight data, three studies used cut-offs other than $25 \mathrm{~kg} / \mathrm{m}^{2}$ and $30 \mathrm{~kg} / \mathrm{m}^{2}$ to classify subjects into distinct groups. Only three studies had an overweight sample as 


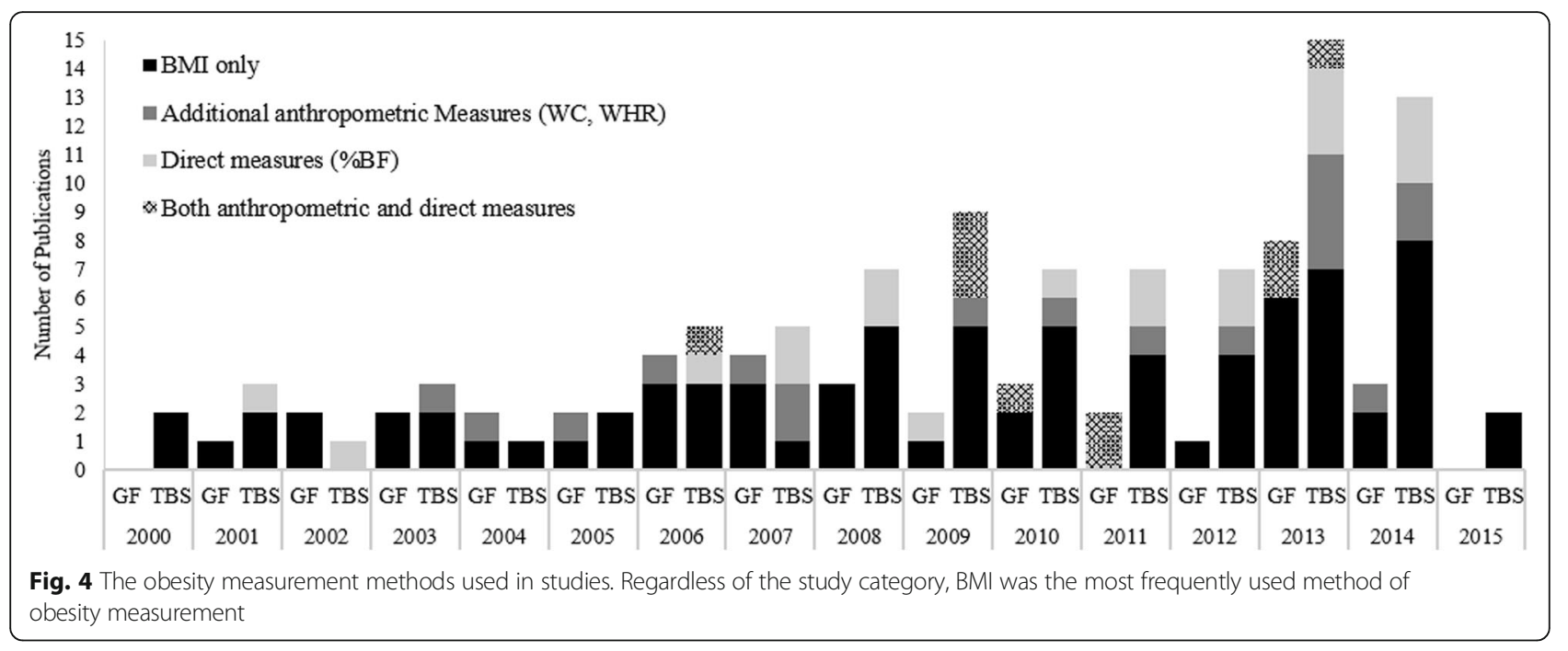

well as obese. The median sample size was 40 (20-306). On average $\sim 60 \%$ of the sample were OW/OB and the majority of reported mean $\mathrm{BMI}$ values were in the range of $35-40 \mathrm{~kg} / \mathrm{m}^{2}$. One Australian study in particular, which used BMI and cut-off values of $23 \mathrm{~kg} / \mathrm{m}^{2}$ and $27.5 \mathrm{~kg} / \mathrm{m}^{2}$, had mean BMI of $30 \mathrm{~kg} / \mathrm{m}^{2}$ for obese. All but three studies reported some significant obesity effect and two reported significant overweight effect. Authors of six studies, out of which five had used multiple anthropometric measures, included a mention of BMI's limitation as a measure of obesity.

Issues related to balance, postural stability, and plantar pressure were discussed by 13 lab-based studies. Subjects were recruited from the general population in all but three studies, two of which had sampled from orthopedic rehabilitation and obesity treatment clinic patients. In one study, \%BF was the primary obesity measurement used, but eight studies used BMI as the primary and only measure. Two other studies used both \%BF and other anthropometric measures, and two studies used both BMI and WHR. It is noted that the two studies with the largest sample sizes used \%BF measured by BIA. One included obesity clinic patients and the subjects in the other were part of a health promotion program for postmenopausal women. The median sample size among studies using only BMI was 40.5 (17-120) out of which on average 51(14) \% were obese. No study in this sub-category included overweight subjects. Two studies, one testing Canadian and one testing Portuguese subjects reported using BMI cut-offs other than 25 and $30 \mathrm{~kg} / \mathrm{m}^{2}$. With the exception of three studies, the average BMI reported for subjects was above $>35 \mathrm{~kg} / \mathrm{m}^{2}$ and in four studies the mean BMI was $>40 \mathrm{~kg} / \mathrm{m}^{2}$. In terms of significance of the obesity effect, two study reported

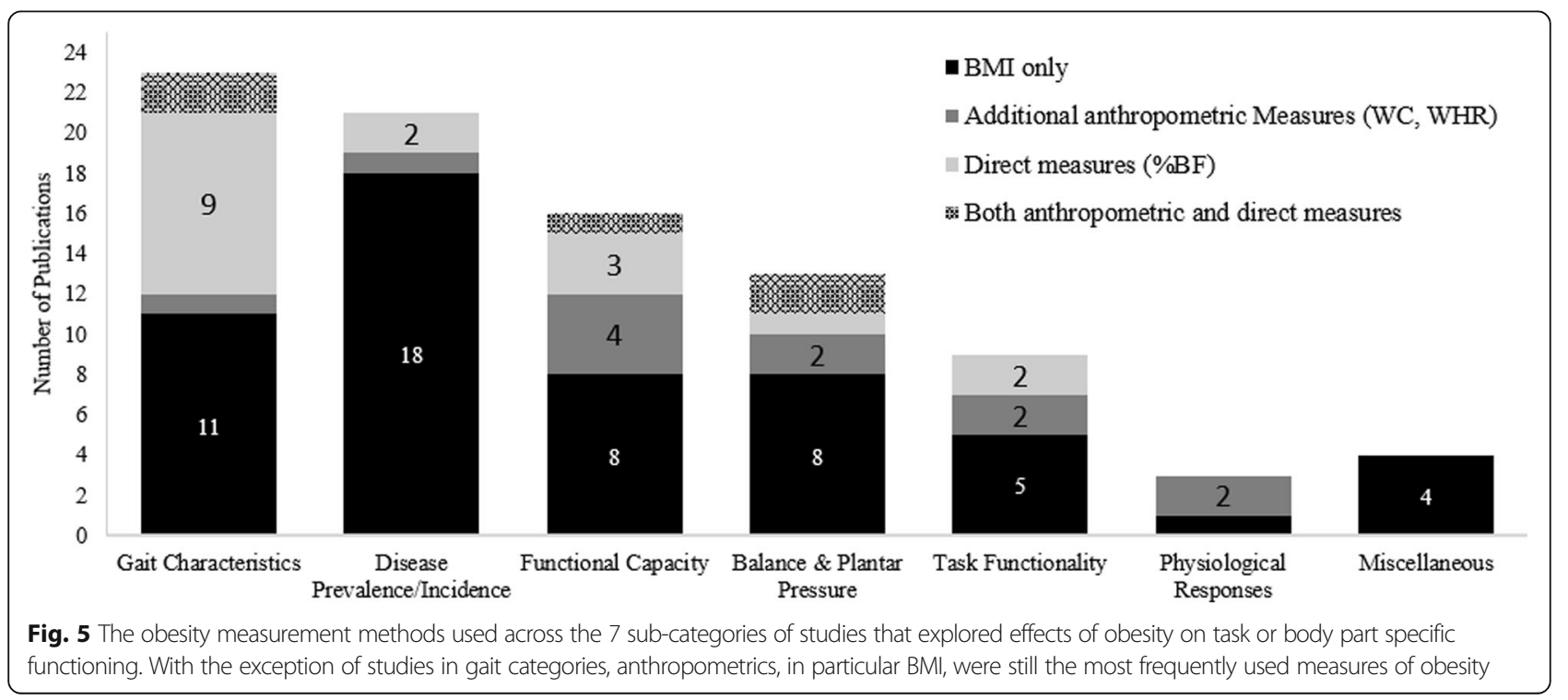


no significant effect and four reported some but not all outcome measures to be significantly affected by obesity. Only two studies had a mention of inadequacy of BMI, and they both used BMI only.

The effects of obesity on functionality while performing specific occupationally-relevant tasks was investigated by nine lab-based studies. All but one study tested physical tasks such as the sit-to-stand movement, lifting, seated reach, cycling, and running. The remaining study focused on cognitive control. Three studies published by Italian authors tested hospital admits or recovering patients for body mass reduction or metabolic disorders. One study from Switzerland also recruited from individuals who were going to participate in a weight loss program at a hospital. Five studies relied on BMI only, while two added \%BF measured by BIA and two added WC. The average sample size was $28.2(\mathrm{SD}=14.5)$ and $60 \%$ of the included sample were obese. Only one study had an overweight group as well as obese. With the exception of two studies, the reported mean BMI for obese group was $>35 \mathrm{~kg} / \mathrm{m}^{2}$. Five studies observed a significant effect of obesity on the performance of the specific tasks tested, while four reported no or partial effect. Three authors discussed how BMI is not the ideal obesity measure although only one used WC in addition.

Three studies discussed changes in physiological responses by obesity and the topics of four studies were not closely pertinent to the above mentioned subgroups. Details of these studies were reported in Table 2.

\section{Discussion}

Researchers worldwide have investigated the effect of obesity (sometimes including overweight) on a wide range of occupationally-relevant outcomes. Experts from diverse disciplines, including but not limited to, public health, medicine, health sciences and engineering, have contributed to our current understanding of the magnitude of an effect of obesity at work [37]. The diversity of scientific disciplines involved in obesity research has both advantages and disadvantages. It allows for more complex aspects of the obesity effect to be revealed by diverse methodologies. However, it increases the risk of misuse of methods due to unfamiliarity. In particular, the investigators' understanding of obesity and the methods to measure it and classify individuals into distinct risk groups can affect the quality of the findings.

The present study focused primarily on examining the use of various obesity measurement methods and secondarily on sampling strategies. Two categories of publications were considered: those investigating the effect of obesity on occupational disease development or business outcomes and those studying how obesity alters task-level performance or functional capacity. As expected, studies in the first category had large sample sizes and were mostly public health studies, carried out by public health professionals. While the samples mostly consisted of participants from the general population or a certain occupation, the large sample sizes justified the use of BMI as the sole obesity measure in over $70 \%$ of these studies. It is noted that the vast majority of the publications in this category failed to report descriptive statistics regarding the obesity status of the obese group included in the sample. This could serve as a critical source of information for comparative analyses. The WHO expert consultation [38] suggests that wherever possible, researchers should use all BMI categories for reporting purposes, in order to facilitate international comparisons (i.e., $18.5,20,23,25,27.5,30,32.5 \mathrm{~kg} / \mathrm{m}^{2}$, and in many populations, $35,37.5$, and $40 \mathrm{~kg} / \mathrm{m}^{2}$ ).

Another issue with studies in the general category is in regard to abdominal obesity. It is often defined using waist circumference, especially in recent years, while waist-hip ratio was often used in earlier years. However, various cut points have been recommended over time, by different health organizations and across countries, and used across studies. Abdominal obesity is a major component of metabolic syndrome, a cluster of metabolic abnormalities that carry an increased risk of cardiovascular diseases and diabetes [39]. However, there is a subset of the obese population that are metabolically healthy and their inclusion in study samples can confound the results. Ortega et al., [40] studied a large cohort of 43,265 individuals and reported that when adjusting for fitness and other confounders, metabolically healthy but obese individuals had lower risk of all-cause mortality, non-fatal and fatal cardiovascular disease, and cancer mortality than their metabolically unhealthy obese counterparts. In their study, over $46 \%$ of the obese sample were metabolically healthy. From the reported exclusion criteria in the studies reported here, it cannot be decided whether obesity would have the same effects in the absence of other components of metabolic syndrome, particularly for outcomes such as healthcare cost, job disability, absenteeism, and presenteeism.

The studies in the second category focused on task-level performance or functional capacity. There are three main points of discussion identified for these studies: 1) selection of obesity measurement(s) (e.g. BMI, WC, \%BF) and the corresponding cut-points to distinguish obese from non-obese, 2) the study participants, both in terms of sample size and the population targeted (e.g. young adults, certain occupation groups, hospital admits), and 3) measurement considerations (e.g. site of measurement for WC). While these factors are all individually important, their interaction may also present a challenge to studies. For instance, when using BMI in a study with a small sample size, recruiting only young adults may be more problematic [41, 42] than 
when a larger group of older adults are classified based on BMI.

In this category, BMI was still the most frequently used obesity classification measure. Overall, the selection of an obesity measure should depend on the hypothesized mechanism by which the obesity effect would manifest. While obesity presents by both changes in anthropometry and metabolic function, acknowledgement of the considered causal pathway is advantageous to study rigor. Also, while obesity morphology may not be as crucial to the outcomes in the studies of the previous category, it is highly relevant to the dependent variables investigated by the studies in this category. In particular, balance and gait parameters are likely to be affected by the distribution of weight in the body, therefore not only obesity status, but also fat distribution needs to be taken into account. BMI by itself fails to do so, however other anthropometric measures such as WC and WHR are able to distinguish central obesity from lower body and general obesity. Across the 36 studies in the two aforementioned sub-categories, only 10 studies used additional anthropometric measures.

Caution should be made in the use of BMI in studies with small samples that include young adults. Statistically significant age dependencies have been reported in the relation between $\% \mathrm{BF}$ and $\mathrm{BMI}$, such that older adults have higher \%BF compared with younger adults with comparable BMIs [25]. WHO expert consultation acknowledges the issue by stating that most studies show the relation between BMI and \%BF to be dependent on age and sex, and also different across ethnic groups. Experts affirmed that Asian populations have different associations between BMI and percentage of body fat than do Western populations [38], however, due to lack of comprehensive data from all Asians, they suggested retaining WHO BMI cut-off points as international classifications. Using ethnic-specific cut-offs may come at the expense of consistency among studies. As such, we observed two studies from Portugal in the balance sub-category that participants were recruited from the general population, one using a BMI cut-off of $25.5 \mathrm{~kg} / \mathrm{m}^{2}$ and the other using $30 \mathrm{~kg} / \mathrm{m}^{2}$ to distinguish obese from non-obese. Arbitrary grouping of subjects, not backed up by ethnic or other expected underlying differences, as was the case in these two studies, should also be minimized. Overall, it is alarming that only $20 \%$ of the studies in this category acknowledged the aforementioned shortcomings of BMI as the obesity measure.

The majority of studies in this category $(\sim 80 \%)$ were observational studies. To isolate an obesity effect, and in contrast to the majority of studies in the first category, subjects were selected such that they were mostly otherwise healthy. The representativeness of this group and the extent to which the findings based from them can be generalized to the overall obese population is concerning. This exclusion of obese with comorbidities from the study samples in this category and their possible inclusion in samples of the first category may contribute to the higher proportion of publications in the first category to report a significant obesity effect in comparison to the second category.

Another issue with the sample representativeness is including only severe obesity (classes II (BMI 35$\left.39.9 \mathrm{~kg} / \mathrm{m}^{2}\right)$ and III $\left(B M I \geq 40 \mathrm{~kg} / \mathrm{m}^{2}\right)$. While this practice may be statistically sound and increase the likelihood of capturing the obesity effect, it again limits the generalizability of the result. For instance, in the United States the prevalence of obesity is estimated to be over $35 \%$ but less than $15 \%$ of the obese population ( $5 \%$ of the total population) are categorized as class II and less than $7 \%(\sim 2.5 \%)$ as class III [43].

There are considerations for proper use of each measurement as well. WC for instance is shown to be significantly different across sites of measurement, postures, phases of respiration, and time since last meal [31]. By following the existing measurement guidelines [44] studies are less prone to error and consistency across subjects and studies is also warranted. Also, practices such as having a single trained staff doing all the measurements when possible, keeping the measurement conditions homogenous across all subjects and using multiple measurements are beneficial for internal validity and worthy of report in research manuscripts.

Overall, we assessed obesity research in the occupational health field and showcased the practices of obesity measurement since 2000. The present study has many strengths, but also some limitations. While obesity has become a global epidemic, this review was limited to PubMed database as well as Google Scholar journal articles available in English, primarily due to the authors' time and language proficiency constraints. Also, studies related to health promotion at work were excluded $[45,46]$. Health risk assessment is a common part of these programs in which obesity status is commonly assessed as a health risk, however the topic of these studies were beyond the scope of this review. Moreover, although the effect of certain work types, such as shift work on the onset of obesity among workers is of importance and has been widely studied [47], this review focused on the obesity effect on occupationally-relevant outcomes.

\section{Conclusion}

Obesity is a serious global public health threat. In order to build up a comprehensive profile of its effects, it is crucial to have easy-to-use yet reliable measures that allow for classification of individuals into distinct risk 
groups. A large body of research has been conducted in the occupational health field regarding obesity. Use of indirect measures such as BMI may be justifiable in large scale public health studies due to their ease of use and low cost. However, due to limitations of these measures, cautious use of them is suggested as the sole obesity measure in small-scale observational studies.

\section{Abbreviations \\ \%BF: Body Fat Percentage; BIA: Bioelectrical Impedance Analysis; BMI: Body Mass Index; DEXA: Energy X-ray Absorptiometry; GF: General Physical or Mental Work-Related Functioning; LBP: Low Back Pain; NIH: National Institute of Health; OA: Osteoarthritis; OW/OB: Overweight/Obese; RoM: Range of Motion; ST: Skinfold Thickness; TBS: Task or Body Part Specific Functioning; WC: Waist Circumference; WHO: World Health Organization; WHR: Waist-Hip Ratio}

\section{Funding}

Funding provided by the Grant or Cooperative Agreement Number, 1 R03 $\mathrm{OH}$ 010547-01, funded by the Centers for Disease Control and Prevention. YW's related effort in this study was supported in part by research grants from the National Institute of Health (NIH, U54 HD070725; 1R01HD06468501A1). Its contents are solely the responsibility of the authors and do not necessarily represent the official views of the funders.

\section{Availability of data and materials}

The datasets generated during the current study are available from the corresponding author on reasonable request.

\section{Authors' contributions}

MGS participated in the design of the study and all the phases of the systematic review and drafted of the manuscript. LAC participated in the design of the study and provided oversight of the review and reviewed the draft of the manuscript. IW provided insight on the analysis of the results and reviewed the draft of the manuscript. All authors read and approved the final manuscript.

\section{Ethics approval and consent to participate}

No IRB approval was sought for this study since it did not involve human subjects.

\section{Consent for publication}

Not applicable.

\section{Competing interests}

The authors declare that they have no competing interests.

\section{Publisher's Note}

Springer Nature remains neutral with regard to jurisdictional claims in published maps and institutional affiliations.

\section{Author details}

'Department of Industrial and Systems Engineering, University at Buffalo, 324 Bell Hall, Buffalo, NY 14260, USA. ²Department of Nutrition and Health Sciences, College of Health, Ball State University, Muncie, IN, USA.

Received: 28 November 2017 Accepted: 21 June 2018

Published online: 01 November 2018

\section{References}

1. World Health Organization. Obesity and overweight. Fact sheet N 311. http://www.who.int/mediacentre/factsheets/fs311/en/ (2015). Accessed 8 May 2017.

2. Ng M, Fleming T, Robinson M, Thomson B, Graetz N, Margono C, Mullany EC, Biryukov S, Abbafati C, Abera SF, Abraham JP. Global, regional, and national prevalence of overweight and obesity in children and adults during 1980-2013: a systematic analysis for the global burden of disease study 2013. Lancet. 2014;384:766-81.

3. Wang Y, Beydoun MA. The obesity epidemic in the United States-gender, age, socioeconomic, racial/ethnic, and geographic characteristics: a systematic review and meta-regression analysis. Epidemiol Rev. 2007;29:6-28.
4. Hubert HB, Feinleib M, McNamara PM, Castelli WP. Obesity as an independent risk factor for cardiovascular disease: a 26-year follow-up of participants in the Framingham heart study. Circulation. 1983;67:968-77.

5. Goldhaber SZ, Grodstein F, Stampfer MJ, Manson JE, Colditz GA, Speizer FE, Willett WC, Hennekens $\mathrm{CH}$. A prospective study of risk factors for pulmonary embolism in women. JAMA. 1997:277:642-5.

6. Powell A, Teichtahl AJ, Wluka AE, Cicuttini FM. Obesity: a preventable risk factor for large joint osteoarthritis which may act through biomechanical factors. Br J Sports Med. 2005;39:4-5.

7. Carroll KK. Obesity as a risk factor for certain types of cancer. Lipids. 1998 Nov 1;33:1055-9.

8. Gilleard W. Functional task limitations in obese adults. Curr Obes Rep. 2012;1:174-80.

9. Cournot MC, Marquie JC, Ansiau D, Martinaud C, Fonds H, Ferrieres J, Ruidavets JB. Relation between body mass index and cognitive function in healthy middle-aged men and women. Neurology. 2006:67:1208-14.

10. Luckhaupt SE, Cohen MA, Li J, Calvert GM. Prevalence of obesity among US workers and associations with occupational factors. Am J Prev Med. 2014:46: 237-48

11. Neovius K, Johansson K, Kark M, Neovius M. Obesity status and sick leave: a systematic review. Obes Rev. 2009;10:17-27.

12. Pollack KM, Sorock GS, Slade MD, Cantley L, Sircar K, Taiwo O, Cullen MR. Association between body mass index and acute traumatic workplace injury in hourly manufacturing employees. Am J Epidemiol. 2007;166:204-11.

13. Schmier JK, Jones ML, Halpern MT. Cost of obesity in the workplace. Scand Work Environ Health. 2006:1:5-11.

14. Sangachin MG, Cavuoto LA. Obesity research in occupational safety and health: a mapping literature review. Proc Human Factors Ergon Soc Ann Meeting. 2016; doi: https://doi.org/10.1177/1541931213601237.

15. World Health Organization. Obesity: preventing and managing the global epidemic. 2000. http://www.who.int/nutrition/publications/obesity/WHO_ TRS_894/en/. Accessed 8 May 2017

16. World Health Organization. Physical status: The use of and interpretation of anthropometry, Report of a WHO Expert Committee. 1995. http://www.who. int/childgrowth/publications/physical_status/en/. Accessed 8 May 2017.

17. Wang Y. Epidemiology of childhood obesity - methodological aspects and guidelines: what is new? Int J Obes. 2004:28:S21-8.

18. Rothman KJ. BMl-related errors in the measurement of obesity. Int J Obes. 2008;32:S56-9.

19. Mullie P, Vansant G, Hulens M, Clarys P, Degrave E. Evaluation of body fat estimated from body mass index and impedance in Belgian male military candidates: comparing two methods for estimating body composition. Mil Med. 2008;173:266-70.

20. Deurenberg P, Andreoli A, Borg P, Kukkonen-Harjula K, de Lorenzo A, van Marken Lichtenbelt WD, Testolin G, Vigano R, Vollaard N. The validity of predicted body fat percentage from body mass index and fromimpedance in samples of five European populations. Eur J Clin Nutr. 2001;1:973-9.

21. Ruderman NB, Schneider SH, Berchtold P. The" metabolically-obese, normal-weight individual. Am J Clin Nutr. 1981;34:1617-21.

22. Dvorak RV, DeNino WF, Ades PA, Poehlman ET. Phenotypic characteristics associated with insulin resistance in metabolically obese but normal-weight young women. Diabetes. 1999:48:2210-4.

23. Karelis AD, St-Pierre DH, Conus F, Rabasa-Lhoret R, Poehlman ET. Metabolic and body composition factors in subgroups of obesity: what do we know? J Clin Endocrinol Metab. 2004;89:2569-75.

24. Harbin G, Shenoy C, Olson J. Ten-year comparison of BMl, body fat, and fitness in the workplace. Am J Ind Med. 2006;49:223-30.

25. Gallagher D, Visser M, Sepulveda D, Pierson RN, Harris T, Heymsfield SB. How useful is body mass index for comparison of body fatness across age, sex, and ethnic groups? Am J Epidemiol. 1996;143:228-39.

26. Wang Y, Rimm EB, Stampfer MJ, Willett WC, Hu FB. Comparison of abdominal adiposity and overall obesity in predicting risk of type 2 diabetes among men. Am J Clin Nutr. 2005;81:555-63.

27. Després JP, Lemieux I, Prud'Homme D. Treatment of obesity: need to focus on high risk abdominally obese patients. Br Med J. 2001:322:716.

28. Piers LS, Soares MJ, Frandsen SL, O'dea K. Indirect estimates of body composition are useful for groups but unreliable in individuals. Int J Obes. 2000;24:1145-52.

29. Ross R, Berentzen T, Bradshaw AJ, Janssen I, Kahn HS, Katzmarzyk PT, Kuk JL, Seidell JC, Snijder MB, Sørensen TI, Després JP. Does the relationship between waist circumference, morbidity and mortality depend on measurement protocol for waist circumference? Obes Rev. 2008;9:312-25. 
30. Lohman TJ, Roache AF, Martorell R. Anthropometric standardization reference manual. Med Sci Sports Exerc. 1992;24:952.

31. Agarwal SK, Misra A, Aggarwal P, Bardia A, Goel R, Vikram NK, Wasir JS, Hussain N, Ramachandran K, Pandey RM. Waist circumference measurement by site, posture, respiratory phase, and meal time: implications for methodology. Obesity. 2009;17:1056-61.

32. Pan WH, Yeh WT, Weng LC. Epidemiology of metabolic syndrome in Asia. Asia Pac J Clin Nutr. 2008;17:37-42.

33. Misra A. Revisions of cutoffs of body mass index to define overweight and obesity are needed for the Asian-ethnic groups. Int J Obes. 2003:27:1294-6.

34. Stevens J. Ethnic-specific cutpoints for obesity vs country-specific guidelines for action. Int J Obes. 2003;27:287-8.

35. Sangachin M, Samadi M, Cavuoto L. Modeling the spread of an obesity intervention through a social network. J Healthcare Eng. 2014;5:293-312.

36. Lee M, Roan M, Smith B. An application of principal component analysis for lower body kinematics between loaded and unloaded walking. J Biomech. 2009;42:2226-30.

37. Khan A, Choudhury N, Uddin S, Hossain L, Baur LA. Longitudinal trends in global obesity research and collaboration: a review using bibliometric metadata. Obes Rev. 2016; https://doi.org/10.1111/obr.12372.

38. World Health Organization Expert Consultation. Appropriate body-mass index for Asian populations and its implications for policy and intervention strategies. Lancet (London, England). 2004;363:157-63.

39. Eckel RH, Grundy SM, Zimmet PZ. The metabolic syndrome. Lancet. 2005; 365:1415-28.

40. Ortega FB, Lee DC, Katzmarzyk PT, Ruiz JR, Sui X, Church TS, Blair SN. The intriguing metabolically healthy but obese phenotype: cardiovascular prognosis and role of fitness. Eur Heart J. 2013;34:389-97.

41. Sangachin MG, Cavuoto LA. Obesity-related changes in prolonged repetitive lifting performance. Appl Ergon. 2016;56:19-26.

42. Pajoutan M, Mehta RK, Cavuoto LA. The effect of obesity on central activation failure during ankle fatigue: a pilot investigation. Fatigue Biomed Health Behavior. 2016:4:115-26.

43. Ogden CL, Carroll MD, Kit BK, Flegal KM. Prevalence of childhood and adult obesity in the United States, 2011-2012. JAMA. 2014;311:806-14.

44. National Institute of Health; National Heart, Lung, and Blood Institute. Joint National Committee on Prevention, Detection, Evaluation, and Treatment of High Blood Pressure. North American Association for the Study of Obesity. The Practical Guide: Identification, Evaluation, and Treatment of Overweight and Obesity in Adults. 2000. https://www.nhlbi.nih.gov/files/docs/ guidelines/prctgd_c.pdf. Accessed 8May 2017.

45. Sangachin MG, Cavuoto LA. Worksite exercise programs why do employees participate? Proc Human Factors Ergon Soc Ann Meet. 2015; https://doi.org/ $10.1177 / 1541931215591187$.

46. Sangachin MG, Gustafson WW, Cavuoto LA. Effect of active workstation use on workload, task performance, and postural and physiological responses. IIE Trans Occup Ergon Hum Factors. 2016;4:67-81.

47. Proper $\mathrm{Kl}$, van de Langenberg $\mathrm{D}$, Rodenburg W, Vermeulen $\mathrm{RC}$, van der Beek AJ, van Steeg H, van Kerkhof LW. The relationship between shift work and metabolic risk factors: a systematic review of longitudinal studies. Am J Prev Med. 2016;50:e147-57.

48. Lee YC, Runnion CK, Pang SC, de Klerk NH, Musk AW. Increased body mass index is related to apparent circumscribed pleural thickening on plain chest radiographs. Am J Ind Med. 2001;39:112-6.

49. Clark S, Rene A, Theurer WM, Marshall M. Association of body mass index and health status in firefighters. J Occup Environ Med. 2002;44:940-6.

50. Poston WS, Haddock CK, Talcott GW, Klesges RC, Lando HA, Peterson A. Are overweight and obese airmen at greater risk of discharge from the United States air Force? Mil Med. 2002;167:585-8.

51. Arbabi S, Wahl WL, Hemmila MR, Kohoyda-Inglis C, Taheri PA, Wang SC. The cushion effect. J Trauma. 2003;54:1090-3.

52. Bungum T, Satterwhite M, Jackson AW, Morrow JR. The relationship of body mass index, medical costs, and job absenteeism. Am J Health Behav. 2003;27:456-62.

53. Moreau M, Valente F, Mak R, Pelfrene E, de Smet P, De Backer G, et al. Obesity, body fat distribution and incidence of sick leave in the Belgian workforce: the Belstress study. Int J Obes Relat Metab Disord. 2004;28:574-82.

54. Pronk NP, Martinson B, Kessler RC, Beck AL, Simon GE, Wang P. The association between work performance and physical activity, cardiorespiratory fitness, and obesity. J Occup Environ Med. 2004:46:19-25.

55. Laitinen J, Nayha S, Kujala V. Body mass index and weight change from adolescence into adulthood, waist-to-hip ratio and perceived work ability among young adults. Int J Obes. 2005;29:697-702.
56. Ricci JA, Chee E. Lost productive time associated with excess weight in the US workforce. J Occup Environ Med. 2005;47:1227-34.

57. Arena VC, Padiyar KR, Burton WN, Schwerha JJ. The impact of body mass index on short-term disability in the workplace. J Occup Environ Med. 2006; 48:1118-24.

58. Cormier $Y$, Israel-Assayag E. Adiposity affects human response to inhaled organic dust. Am J Ind Med. 2006;49:281-5.

59. Nishitani N, Sakakibara H. Relationship of obesity to job stress and eating behavior in male Japanese workers. Int J Obes. 2006;30:528-33.

60. Wang F, McDonald T, Bender J, Reffitt B, Miller A, Edington DW. Association of healthcare costs with per unit body mass index increase. J Occup Environ Med. 2006:48:668-74.

61. Østbye T, Dement JM, Krause KM. Obesity and workers' compensation: results from the Duke health and safety surveillance system. Arch Intern Med. 2007;167:766-73.

62. Charles LE, Fekedulegn D, McCall T, Burchfiel CM, Andrew ME, Violanti JM. Obesity, white blood cell counts, and platelet counts among police officers. Obesity (Silver Spring). 2007;15:2846-54.

63. Finkelstein EA, Chen $\mathrm{H}$, Prabhu M, Trogdon JG, Corso PS. The relationship between obesity and injuries among US adults. Am J Health Promot. 2007; 21:460-8.

64. Jans MP, van den Heuvel SG, Hildebrandt VH, Bongers PM. Overweight and obesity as predictors of absenteeism in the working population of the Netherlands. J Occup Environ Med. 2007:49:975-80.

65. Gates DM, Succop P, Brehm BJ, Gillespie GL, Sommers BD. Obesity and presenteeism: the impact of body mass index on workplace productivity. J Occup Environ Med. 2008:50:39-45

66. Soteriades ES, Hauser R, Kawachi I, Christiani DC, Kales SN. Obesity and risk of job disability in male firefighters. Occup Med. 2008;58:245-50.

67. Claessen H, Arndt V, Drath C, Brenner H. Overweight, obesity and risk of work disability: a cohort study of construction workers in Germany. Occup Environ Med. 2009:66:402-9.

68. Vissers D, Baeyens JP, Truijen S, Ides K, Vercruysse CC, Van Gaal L. The effect of whole body vibration short-term exercises on respiratory gas exchange in overweight and obese women. Phys Sportsmed. 2009;37:88-94.

69. Bedno SA, Li Y, Han W, Cowan DN, Scott CT, Cavicchia MA, et al. Exertional heat illness among overweight US Army recruits in basic training. Aviat Space Environ Med. 2010;81:107-11.

70. Robroek SJ, Van den Berg TI, Plat JF, Burdorf A. The role of obesity and lifestyle behaviours in a productive workforce. Occup Environ Med. 2011;68: 134-9.

71. Vincent HK, Lamb KM, Day TI, Tillman SM, Vincent KR, George SZ. Morbid obesity is associated with fear of movement and lower quality of life in patients with knee pain-related diagnoses. PM R. 2010;2:713-22.

72. Cowan D, Bedno S, Urban N, Yi B, Niebuhr D. Musculoskeletal injuries among overweight army trainees: incidence and health care utilization. Occup Med. 2011;61:247-52.

73. Poston WS, Jitnarin N, Haddock CK, Jahnke SA, Tuley BC. Obesity and injuryrelated absenteeism in a population-based firefighter cohort. Obesity (Silver Spring). 2011;19:2076-81

74. Haukka E, Ojajarvi A, Takala EP, Viikari-Juntura E, Leino-Arjas P. Physical workload, leisure-time physical activity, obesity and smoking as predictors of multisite musculoskeletal pain. A 2-year prospective study of kitchen workers. Occup Environ Med. 2012;69:485-92.

75. Caberlon CF, Padoin AV, Mottin CC. Importance of musculoskeletal pain in work activities in obese individuals. Obes Surg. 2013;23:2092-5.

76. Gubata ME, Urban N, Cowan DN, Niebuhr DW. A prospective study of physical fitness, obesity, and the subsequent risk of mental disorders among healthy young adults in army training. J Psychosom Res. 2013;75:43-8.

77. Jahnke SA, Poston WS, Haddock CK, Jitnarin N. Obesity and incident injury among career firefighters in the Central United States. Obesity (Silver Spring). 2013;21:1505-8.

78. Kouvonen A, Kivimaki M, Oksanen T, Pentti J, De Vogli R, Virtanen M, Vahtera J. Obesity and occupational injury: a prospective cohort study of 69,515 public sector employees. PLoS One. 2013;8:e77178.

79. Lin TC, Verma SK, Courtney TK. Does obesity contribute to non-fatal occupational injury? Evidence from the National Longitudinal Survey of youth. Scand J Work Environ Health. 2013;39:268-75.

80. Roos E, Laaksonen M, Rahkonen O, Lahelma E, Lallukka T. Relative weight and disability retirement: a prospective cohort study. Scand J Work Environ Health. 2013;39:259-67. 
81. Van der Starre RE, Coffeng JK, Hendriksen IJ, van Mechelen W, Boot CR. Associations between overweight, obesity, health measures and need for recovery in office employees: a cross-sectional analysis. BMC Public Health. 2013;13:1207.

82. Viester $L$, Verhagen EA, Oude Hengel KM, Koppes LL, van der Beek AJ, Bongers PM. The relation between body mass index and musculoskeletal symptoms in the working population. BMC Musculoskelet Disord. 2013;14:238.

83. Gonzales MM, Kaur S, Eagan DE, Goudarzi K, Pasha E, Doan DC, et al. Central adiposity and the functional magnetic resonance imaging response to cognitive challenge. Int J Obes. 2014;38:1193-9.

84. Smith TJ, White A, Hadden L, Young AJ, Marriott BP. Associations between mental health disorders and body mass index among military personnel. Am J Health Behav. 2014;38:529-40.

85. DeVita P, Hortobagyi T. Obesity is not associated with increased knee joint torque and power during level walking. J Biomech. 2003;36:1355-62.

86. Browning RC, Baker EA, Herron JA, Kram R. Effects of obesity and sex on the energetic cost and preferred speed of walking. J Appl Physiol. 2006;100:390-8.

87. Browning RC, Kram R. Effects of obesity on the biomechanics of walking at different speeds. Med Sci Sports Exerc. 2007;39:1632-41.

88. Lafortuna CL, Agosti F, Galli R, Busti C, Lazzer S, Sartorio A. The energetic and cardiovascular response to treadmill walking and cycle ergometer exercise in obese women. Eur J Appl Physiol. 2008;103:707-17.

89. Lai PP, Leung AK, Li AN, Zhang M. Three-dimensional gait analysis of obese adults. Clin Biomech (Bristol, Avon). 2008;23:S2-6.

90. Browning RC, McGowan CP, Kram R. Obesity does not increase external mechanical work per kilogram body mass during walking. J Biomech. 2009; 42:2273-8.

91. Malatesta D, Vismara L, Menegoni F, Galli M, Romei M, Capodaglio P. Mechanical external work and recovery at preferred walking speed in obese subjects. Med Sci Sports Exerc. 2009;41:426-34.

92. Ko S, Stenholm S, Ferrucci L. Characteristic gait patterns in older adults with obesity-results from the Baltimore longitudinal study of aging. J Biomech. 2010;43:1104-10.

93. Russell EM, Braun B, Hamill J. Does stride length influence metabolic cost and biomechanical risk factors for knee osteoarthritis in obese women? Clin Biomech (Bristol, Avon). 2010;25:438-43.

94. Blaszczyk JW, Plewa M, Cieslinska-Swider J, Bacik B, Zahorska-Markiewicz B, Markiewicz A. Impact of excess body weight on walking at the preferred speed. Acta Neurobiol Exp (Wars). 2011;71:528-40.

95. Ehlen KA, Reiser RF 2nd, Browning RC. Energetics and biomechanics of inclined treadmill walking in obese adults. Med Sci Sports Exerc. 2011;43:1251-9.

96. Cimolin V, Vismara L, Galli M, Zaina F, Negrini S, Capodaglio P. Effects of obesity and chronic low back pain on gait. J Neuroeng Rehabil. 2011;8:55.

97. Russell EM, Hamill J. Lateral wedges decrease biomechanical risk factors for knee osteoarthritis in obese women. J Biomech. 2011;44:2286-91.

98. Wu X, Lockhart TE, Yeoh HT. Effects of obesity on slip-induced fall risks among young male adults. J Biomech. 2012;45:1042-7.

99. Harding GT, Hubley-Kozey CL, Dunbar MJ, Stanish WD, Astephen Wilson JL. Body mass index affects knee joint mechanics during gait differently with and without moderate knee osteoarthritis. Osteoarthr Cartil. 2012;20:1234-42.

100. Russell EM, Miller RH, Umberger BR, Hamill J. Lateral wedges alter mediolateral load distributions at the knee joint in obese individuals. J Orthop Res. 2013;31:665-71.

101. Browning RC, Reynolds MM, Board WJ, Walters KA, Reiser RF 2nd. Obesity does not impair walking economy across a range of speeds and grades. J Appl Physiol. 2013;114:1125-31.

102. Ranavolo A, Donini LM, Mari S, Serrao M, Silvetti A, lavicoli S, et al. Lowerlimb joint coordination pattern in obese subjects. Biomed Res Int. 2013; https://doi.org/10.1155/2013/142323.

103. Cimolin V, Vismara L, Galli M, Grugni G, Cau N, Capodaglio P. Gait strategy in genetically obese patients: a 7-year follow up. Res Dev Disabil. 2014;35:1501-6.

104. Haight DJ, Lerner ZF, Board WJ, Browning RC. A comparison of slow, uphill and fast, level walking on lower extremity biomechanics and tibiofemoral joint loading in obese and nonobese adults. J Orthop Res. 2014;32:324-30

105. Page Glave A, Di Brezzo R, Applegate DK, Olson JM. The effects of obesity classification method on select kinematic gait variables in adult females. J Sports Med Phys Fitness. 2014;54:197-202.

106. Cau N, Cimolin V, Galli M, Precilios H, Tacchini E, Santovito C, Capodaglio P. Center of pressure displacements during gait initiation in individuals with obesity. J Neuroeng Rehabil. 2014;11:82.

107. Lerner ZF, Board WJ, Browning RC. Effects of obesity on lower extremity muscle function during walking at two speeds. Gait Posture. 2014;39:978-84.
108. Kouyoumdjian JA, Morita MD, Rocha PR, Miranda RC, Gouveia GM. Body mass index and carpal tunnel syndrome. Arq Neuropsiquiatr. 2000;58:252-6.

109. Young SY, Gunzenhauser JD, Malone KE, McTiernan A. Body mass index and asthma in the military population of the northwestern United States. Arch Intern Med. 2001;161:1605-11.

110. Bland JD. The relationship of obesity, age, and carpal tunnel syndrome: more complex than was thought? Muscle Nerve. 2005;32:527-32.

111. Liuke M, Solovieva S, Lamminen A, Luoma K, Leino-Arjas P, Luukkonen R, Riihimaki $\mathrm{H}$. Disc degeneration of the lumbar spine in relation to overweight. Int J Obes. 2005;29:903-8.

112. Dagan Y, Doljansky JT, Green A, Weiner A. Body mass index (BMI) as a firstline screening criterion for detection of excessive daytime sleepiness among professional drivers. Traffic Inj Prev. 2006;7:44-8.

113. Zhao LJ, Liu YJ, Liu PY, Hamilton J, Recker RR, Deng HW. Relationship of obesity with osteoporosis. J Clin Endocrinol Metab. 2007:92:1640-6.

114. Sharifi-Mollayousefi A, Yazdchi-Marandi M, Ayramlou H, Heidari P, Salavati A, Zarrintan S, Sharifi-Mollayousefi A. Assessment of body mass index and hand anthropometric measurements as independent risk factors for carpal tunnel syndrome. Folia Morphol (Warsz). 2008;67:36-42.

115. Grotle M, Hagen KB, Natvig B, Dahl FA, Kvien TK. Obesity and osteoarthritis in knee, hip and/or hand: an epidemiological study in the general population with 10 years follow-up. BMC Musculoskelet Disord. 2008;9:132.

116. Noorloos D, Tersteeg L, Tiemessen IJ, Hulshof CT, Frings-Dresen MH. Does body mass index increase the risk of low back pain in a population exposed to whole body vibration? Appl Ergon. 2008;39:779-85.

117. Toivanen AT, Heliovaara M, Impivaara O, Arokoski JP, Knekt P, Lauren H, Kroger $\mathrm{H}$. Obesity, physically demanding work and traumatic knee injury are major risk factors for knee osteoarthritis-a population-based study with a follow-up of 22 years. Rheumatology (Oxford). 2010;49:308-14.

118. Vismara L, Menegoni F, Zaina F, Galli M, Negrini S, Capodaglio P. Effect of obesity and low back pain on spinal mobility: a cross sectional study in women. J Neuroeng Rehabil. 2010;7:3.

119. Wood D, Goodnight S, Haig AJ, Nasari T. Body mass index, but not blood pressure is related to the level of pain in persons with chronic pain. J Back Musculoskelet Rehabil. 2011:24:111-5.

120. Ackerman IN, Osborne RH. Obesity and increased burden of hip and knee joint disease in Australia: results from a national survey. BMC Musculoskelet Disord. 2012:13:254.

121. Jensen JN, Holtermann A, Clausen T, Mortensen OS, Carneiro IG, Andersen $\mathrm{LL}$. The greatest risk for low-back pain among newly educated female health care workers; body weight or physical work load? BMC Musculoskelet Disord. 2012;13:87.

122. Freedman Silvernail J, Milner CE, Thompson D, Zhang S, Zhao X. The influence of body mass index and velocity on knee biomechanics during walking. Gait Posture. 2013;37:575-9.

123. Seror $P$, Seror R. Prevalence of obesity and obesity as a risk factor in patients with severe median nerve lesion at the wrist. Joint Bone Spine. 2013;80: 632-7.

124. Martin KR, Kuh D, Harris TB, Guralnik JM, Coggon D, Wills AK. Body mass index, occupational activity, and leisure-time physical activity: an exploration of risk factors and modifiers for knee osteoarthritis in the 1946 British birth cohort. BMC Musculoskelet Disord. 2013;14:219.

125. Romero-Vargas S, Zarate-Kalfopulos B, Otero-Camara E, Rosales-Olivarez L, Alpizar-Aguirre A, Morales-Hernandez E, et al. The impact of body mass index and central obesity on the spino-pelvic parameters: a correlation study. Eur Spine J. 2013;22:878-82.

126. Messier SP, Pater M, Beavers DP, Legault C, Loeser RF, Hunter DJ, DeVita P. Influences of alignment and obesity on knee joint loading in osteoarthritic gait. Osteoarthr Cartil. 2014;22:912-7.

127. Urquhart DM, Phyomaung PP, Wluka AE, Sim MR, Forbes A, Jones G, Davies M, Cicuttini FM. Is there a relationship between occupational activities and low back pain in obese, middle-aged women? Climacteric. 2014;17:87-91.

128. Evanoff A, Sabbath EL, Carton M, Czernichow S, Zins M, Leclerc A, et al. Does obesity modify the relationship between exposure to occupational factors and musculoskeletal pain in men? Results from the GAZEL cohort study. PLoS One. 2014;9:e109633.

129. Hulens M, Vansant G, Lysens R, Claessens A, Muls E. Exercise capacity in lean versus obese women. Scand J Med Sci Sports. 2001;11:305-9.

130. Hulens M, Vansant G, Lysens R, Claessens AL, Muls E. Assessment of isokinetic muscle strength in women who are obese. J Orthop Sports Phys Ther. 2002;32:347-56. 
131. Maffiuletti NA, Jubeau M, Munzinger U, Bizzini M, Agosti F, De Col A, et al. Differences in quadriceps muscle strength and fatigue between lean and obese subjects. Eur J Appl Physiol. 2007;101:51-9.

132. Segal NA, Yack HJ, Khole P. Weight, rather than obesity distribution, explains peak external knee adduction moment during level gait. Am J Phys Med Rehabil. 2009:88:180-8. quiz 9-91, 246

133. Capodaglio P, Vismara L, Menegoni F, Baccalaro G, Galli M, Grugni G. Strength characterization of knee flexor and extensor muscles in Prader-Willi and obese patients. BMC Musculoskelet Disord. 2009;10:47.

134. Singh D, Park W, Levy MS. Obesity does not reduce maximum acceptable weights of lift. Appl Ergon. 2009;40:1-7.

135. Faria A, Gabriel R, Abrantes J, Bras R, Moreira H. Triceps-surae musculotendinous stiffness: relative differences between obese and non-obese postmenopausal women. Clin Biomech (Bristol, Avon). 2009;24:866-71.

136. Park W, Ramachandran J, Weisman $P$, Jung ES. Obesity effect on male active joint range of motion. Ergonomics. 2010;53(1):102-8.

137. Blazek K, Asay JL, Erhart-Hledik J, Andriacchi T. Adduction moment increases with age in healthy obese individuals. J Orthop Res. 2013;31:1414-22.

138. Cavuoto LA, Nussbaum MA. Differences in functional performance of the shoulder musculature with obesity and aging. Int J Ind Ergon. 2013;43:393-9.

139. Hamilton MA, Strawderman L, Babski-Reeves K, Hale B. Effects of BMI and task parameters on joint angles during simulated small parts assembly. Int J Ind Ergon. 2013;43:417-24

140. Mignardot JB, Olivier I, Promayon E, Nougier V. Origins of balance disorders during a daily living movement in obese: can biomechanical factors explain everything? PLoS One. 2013;8:e60491.

141. Wearing SC, Hooper SL, Grigg NL, Nolan G, Smeathers JE. Overweight and obesity alters the cumulative transverse strain in the Achilles tendon immediately following exercise. J Bodyw Mov Ther. 2013;17:316-21.

142. Cavuoto LA, Nussbaum MA. Obesity-related differences in muscular capacity during sustained isometric exertions. Appl Ergon. 2013:44:254-60.

143. Cavuoto LA, Nussbaum MA. The influences of obesity and age on functional performance during intermittent upper extremity tasks. J Occup Environ Hyg. 2014;11:583-90.

144. Mehta RK, Cavuoto LA. The effects of obesity, age, and relative workload levels on handgrip endurance. Appl Ergon. 2015;46:91-5.

145. Hills AP, Hennig EM, McDonald M, Bar-Or O. Plantar pressure differences between obese and non-obese adults: a biomechanical analysis. Int J Obes Relat Metab Disord. 2001;25:1674-9.

146. Gravante G, Russo G, Pomara F, Ridola C. Comparison of ground reaction forces between obese and control young adults during quiet standing on a baropodometric platform. Clin Biomech (Bristol, Avon). 2003;18:780-2.

147. Birtane $M$, Tuna $H$. The evaluation of plantar pressure distribution in obese and non-obese adults. Clin Biomech. 2004;19:1055-9.

148. Berrigan F, Simoneau M, Tremblay A, Hue O, Teasdale N. Influence of obesity on accurate and rapid arm movement performed from a standing posture. Int J Obes. 2006;30:1750-7.

149. Teh E, Teng LF, Acharya R, Ha TP, Goh E, Min LC. Static and frequency domain analysis of plantar pressure distribution in obese and non-obese subjects. J Bodyw Mov Ther. 2006;10:127-33.

150. Singh D, Park W, Levy MS, Jung ES. The effects of obesity and standing time on postural sway during prolonged quiet standing. Ergonomics. 2009;52:977-86.

151. Blaszczyk JW, Cieslinska-Swider J, Plewa M, Zahorska-Markiewicz B, Markiewicz A. Effects of excessive body weight on postural control. J Biomech. 2009:42:1295-300.

152. Park W, Singh DP, Levy MS, Jung ES. Obesity effect on perceived postural stress during static posture maintenance tasks. Ergonomics. 2009;52:1169-82.

153. Menegoni F, Galli M, Tacchini E, Vismara L, Cavigioli M, Capodaglio P. Genderspecific effect of obesity on balance. Obesity (Silver Spring). 2009;17:1951-6.

154. Monteiro M, Gabriel R, Aranha J, Neves e Castro M, Sousa M, Moreira M. Influence of obesity and sarcopenic obesity on plantar pressure of postmenopausal women. Clin Biomech (Bristol, Avon). 2010;25:461-7.

155. Miller EM, Matrangola SL, Madigan ML. Effects of obesity on balance recovery from small postural perturbations. Ergonomics. 2011;54:547-54.

156. Matrangola SL, Madigan ML. The effects of obesity on balance recovery using an ankle strategy. Hum Mov Sci. 2011;30:584-95.

157. Peduzzi de Castro M, Abreu S, Pinto V, Santos R, Machado L, Vaz M, VilasBoas JP. Influence of pressure-relief insoles developed for loaded gait (backpackers and obese people) on plantar pressure distribution and ground reaction forces. Appl Ergon. 2014;45:1028-34.
158. Galli M, Crivellini M, Sibella F, Montesano A, Bertocco P, Parisio C. Sit-tostand movement analysis in obese subjects. Int J Obes Relat Metab Disord. 2000;24:1488-92.

159. Sibella F, Galli M, Romei M, Montesano A, Crivellini M. Biomechanical analysis of sit-to-stand movement in normal and obese subjects. Clin Biomech. 2003;18:745-50.

160. Lafortuna CL, Proietti M, Agosti F, Sartorio A. The energy cost of cycling in young obese women. Eur J Appl Physiol. 2006;97:16-25.

161. Gilleard W, Smith T. Effect of obesity on posture and hip joint moments during a standing task, and trunk forward flexion motion. Int J Obes. 2007;31:267-71.

162. Xu X, Mirka GA, Hsiang SM. The effects of obesity on lifting performance. Appl Ergon. 2008;39:93-8.

163. Taboga P, Lazzer S, Fessehatsion R, Agosti F, Sartorio A, di Prampero PE. Energetics and mechanics of running men: the influence of body mass. Eur J Appl Physiol. 2012;112:4027-33.

164. Hendrick OM, Luo X, Zhang S, Li CS. Saliency processing and obesity: a preliminary imaging study of the stop signal task. Obesity (Silver Spring). 2012;20:1796-802

165. Singh B, Brown TD, Callaghan JJ, Yack HJ. Abdomen-thigh contact during forward reaching tasks in obese individuals. J Appl Biomech. 2013;29:517-24

166. Schmid S, Armand S, Pataky Z, Golay A, Allet L. The relationship between different body mass index categories and chair rise performance in adult women. J Appl Biomech. 2013;29:705-11.

167. Willenberg T, Schumacher A, Amann-Vesti B, Jacomella V, Thalhammer C, Diehm N, Baumgartner I, Husmann M. Impact of obesity on venous hemodynamics of the lower limbs. J Vasc Surg. 2010;52:664-8.

168. Engelberger RP, Indermuhle A, Baumann F, Fahrni J, Diehm N, Kucher N, Egermann U, Laederach K, Baumgartner I, Willenberg T. Diurnal changes of lower leg volume in obese and non-obese subjects. Int J Obes. 2014;38:801-5.

169. Yang B, Sun Z, Cao F, Zhao H, Li C, Zhang J. Obesity is a risk factor for acute mountain sickness: a prospective study in Tibet railway construction workers on Tibetan plateau. Eur Rev Med Pharmacol Sci. 2015;19:119-22.

170. Menegoni F, Vismara L, Capodaglio P, Crivellini M, Galli M. Kinematics of trunk movements: protocol design and application in obese females. J Appl Biomater Biomech. 2007:6:178-85.

171. Forman J, Lopez-Valdes FJ, Lessley D, Kindig M, Kent R, Bostrom O. The effect of obesity on the restraint of automobile occupants. Ann Adv Automot Med. 2009;53:25-40.

172. Lerner ZF, Board WJ, Browning RC. Effects of an obesity-specific marker set on estimated muscle and joint forces in walking. Med Sci Sports Exerc. 2014:46:1261-7.

173. Thorp AA, Kingwell BA, Owen N, Dunstan DW. Breaking up workplace sitting time with intermittent standing bouts improves fatigue and musculoskeletal discomfort in overweight/obese office workers. Occup Environ Med. 2014;71:765-71

\section{Ready to submit your research? Choose BMC and benefit from:}

- fast, convenient online submission

- thorough peer review by experienced researchers in your field

- rapid publication on acceptance

- support for research data, including large and complex data types

- gold Open Access which fosters wider collaboration and increased citations

- maximum visibility for your research: over $100 \mathrm{M}$ website views per year

At BMC, research is always in progress.

Learn more biomedcentral.com/submissions 